\title{
Errors in Estimating Unexpected Accruals in the Presence of Large Changes in Net External Financing
}

\author{
Yaowen Shan \\ (University of Technology, Sydney) \\ Stephen Taylor* \\ (University of Technology, Sydney) \\ Terry Walter \\ (University of Technology, Sydney)
}

March 2009

Keywords: Accruals, earnings management, unexpected accruals, net external financing

The authors acknowledge support from the Accounting and Audit Quality Research Program sponsored by the Capital Markets Co-operative Research Centre (CMCRC Ltd), a research centre funded by the Federal Government of Australia. The authors are grateful for suggestions by Robert Bushman, Paul Healy, Tom Smith, Nasser Spear as well as attendees at the 2009 UTS Accounting Summer Research School.

* Corresponding author

School of Accounting

University of Technology, Sydney

PO Box 123 Broadway

NSW 2007 Australia

Stephen.Taylor@uts.edu.au 


\title{
Errors in Estimating Unexpected Accruals in the Presence of Large Changes in Net External Financing
}

\begin{abstract}
We demonstrate that the articulation among accruals, cash flows and revenues which is typically assumed in tests of earnings management does not hold when large (positive or negative) external financing activities are present. Our study provides evidence that managers' "normal" operating decisions associated with net external financing activities are likely to lead to economically and statistically significant measurement errors in unexpected accruals. This is a serious concern given the frequency with which the partitioning variable used to identify instances of alleged earnings management is correlated with significant movements in net external financing. Simulation tests show that even at modest levels of net external financing changes, rejection frequencies for the null hypothesis of no earnings management rise dramatically. This result underscores the importance of additional specification tests being conducted to control for estimation biases in unexpected accruals associated with external financing. We suggest the use of matched-firm approach using industry and external financing matches. Using this approach, we demonstrate that prior conclusions about the existence of earnings management around open market repurchases (Gong et al. 2008) do not appear robust when attempts are made to control for the effect on expected accruals of large changes in net external financing.
\end{abstract}




\section{Introduction}

Earnings management has been the focus of extensive research in accounting. In order to measure the extent of managed earnings, researchers typically rely on estimates of unexpected accruals which are based on a presumed articulation between accruals and a firm's current period cash flows and/or near-term changes in revenues. While this research effort has provided numerous insights into the causes and consequences of earnings management it is also widely accepted that the existing accruals expectation models do not work well in identifying earnings management practices. Our paper adds to these concerns by demonstrating analytically and empirically that the presumed articulation among accruals, cash flows and revenues does not hold in the event of significant net external financing changes. In such circumstances, we show that commonly-used unexpected accruals measures are likely to contain economically and statistically significant measurement errors.

Recent evidence of measurement errors in unexpected accruals induced by external financing is provided by Ball and Shivakumar (2008), who examine the extent of earnings management around initial public offerings (IPOs). They suggest two fundamental concerns with prior evidence claiming that IPO firms manage earnings upwards around the IPO. First, they argue that researchers typically pay insufficient attention to reasons as to why such firms may not want to engage in earnings management and/or why earnings management is likely to be expected and hence, detected. ${ }^{1}$ Second, and of more direct relevance to our analysis, they argue that a firm experiencing a large external financing inflow tends to use the received cash proceeds to increase its inventory and accounts receivable as a consequence of expanding its operations. These activities lead to dramatic increases in a firm's working capital, with a rate of change for working capital significantly higher than that for revenues. Thus,

\footnotetext{
${ }^{1}$ One exception is Shivakumar (2000), who argues that investors rationally undo the effects of earnings management occurring prior to a seasoned equity offering (SEO).
} 
these transactions would be identified by existing models of unexpected accruals as income-increasing earnings management, even after controlling for the change in sales. $^{2}$ This is true irrespective of whether accruals are estimated from changes in successive balance sheets or from statements of cash flow. ${ }^{3}$ As Ball and Shivakumar note, current accruals of this type have nothing to do with earnings management, but are simply a reflection of the rational investment of IPO proceeds in operating activities.

While serving to raise serious questions about prior evidence of IPO earnings management, the analysis of Ball and Shivakumar (2008) also suggests a more general question, namely the effect on unexpected accrual measurement of significant net financing changes. For example, applying exactly the same reasoning, unexpected accruals models would likely categorize firms with large external financing cash outflows as engaging in income-decreasing earnings management. Many of the circumstances which give rise to expectations of possible earnings management are related to significant changes in net external financing, such as the sale of equity or debt, or significant adjustments by means of stock buybacks or debt reductions. ${ }^{4}$ Moreover, significant changes in net external financing, whether debt or equity-related, are likely to be correlated with many other circumstances alleged to give rise to an incentive to manage earnings. We therefore believe that a broader investigation of the effect of external financing changes is warranted, where external financing refers to both debt and equity. It is also worth noting that large net external financing events are reasonably common for Compustat firms. For example, Leary and Roberts (2005, Table III p. 2601) show that in 35,149 out of 127,308 firm quarters (i.e., $27.6 \%$ or just over once per calendar year on average) in their analysis of firms' capital structures between 1984 and 2001 there is a large debt issue (16,021 cases), debt retirement (10,920 cases), equity

\footnotetext{
2 Similarly, any attempt to pay-off pre-IPO operating liabilities is likely to be interpreted as income-increasing earnings management.

3 This helps explain the finding in Ball and Shivakumar that the data underlying prior evidence of IPO earnings management (Teoh et al. 1998) show a 600.39\% average increase in accounts receivable for the quartile of firms with the most overstated earnings.

${ }^{4}$ Fields et al. (2001) provide an extensive overview of much of this research. Studies with implications for capital market behaviour are also reviewed by Kothari (2001).
} 
issue $(6,867$ cases $)$ or equity repurchase $(5,723$ cases $)$. Moreover, these financing events are large; with the median value of the financing event to firm market capitalization in the four groups being $12 \%, 15 \%, 9 \%$ and $2 \%$ respectively (Table IV, $p$. 2603).

We begin by investigating the relationship between accounting accruals and a firm's net external financing. Accounting identities suggest that external financing and firm performance are two major contributors to the firm's change in net operating assets, which provide a comprehensive measure of total accruals (Dechow et al. 2008; Richardson et al. 2005). Because the change in non-cash working capital, which is a part of the change in net operating assets, forms the core of the commonly used accruals measures (Dechow and Dichev 2002; Hribar and Collins 2002), both external financing and firm performance are positively associated with accounting accruals, regardless of the presence of earnings management.

If accounting accruals are correctly decomposed into their unexpected and expected components and if external financing is not associated with the identified stimulus of earnings management, the positive relation between external financing and accounting accruals would not produce measurement errors in unexpected accruals. However, this is unlikely to be the case. Our univariate correlation analysis demonstrates a significant positive correlation between estimates of unexpected accruals and external financing, indicating that the measurement error in unexpected accruals is positively associated with external financing. In other words, the empirical evidence suggests a systematic bias in estimates of expected accruals that arises from the positive relationship between external financing and accounting accruals. We show that a firm's operating decisions and the resulting accruals properties are more complex than those previously characterized by unexpected accruals models. By assuming that a firm's normal, expected accruals decisions are predicted by current period cash flows and near term changes in sales, commonly-used unexpected accruals models are likely to erroneously classify firms with large external financing cash inflows (outflows) as 
reporting positive (negative) unexpected accruals.

Based upon the above observations, we provide empirical evidence that, on average, unexpected accruals estimates from the most widely used models of expected accruals exhibit a positive bias for firms with large external financing cash inflows, while unexpected accruals of firms with large external financing cash outflows exhibit a negative bias. To show these biases, we sort firms into quartiles each year based on net external financing, and compare the unexpected accruals measures across quartiles. We consider several of the most popular unexpected accruals models, namely the modified Jones model (Dechow et al. 1995), the Dechow-Dichev model (Dechow and Dichev 2002), the McNichols's modification to the Dechow-Dichev model (McNichols 2002), and the modified Jones model with a control for firm performance (Kothari et al. 2005).

We explore the extent to which these biases affect statistical inferences in tests of earnings management. By applying the framework of McNichols and Wilson (1988), we estimate the bias induced by failing to control for external financing. In particular, we show that the unexpected accruals models are correctly specified when a control for external financing is introduced by either of the following two approaches: (1) the regression-based approach that includes net external financing as an additional regressor in the unexpected accruals model; and (2) the matched-firm approach using industry and net external financing for the matching. The results suggest that the bias induced by external financing is economically significant, ranging from $0.2 \%$ to $3.5 \%$ of average total assets for different unexpected accruals measures.

In addition, we examine the potential impact of external financing on statistical inferences in tests of earnings management. We regress unexpected accruals on two indicator variables for large external financing, and find the estimated coefficients on the indicator variables are all significant at the $1 \%$ level for unexpected accruals measures estimated without a control for external financing. Moreover, we conduct 
simulations to examine the type I errors for different unexpected accruals measures with $0 \%-100 \%$ of the sample contaminated by firms with large net external financing. We report the percentage of time in 250 simulated samples that the null hypotheses of non-negative and non-positive unexpected accruals are rejected. The rejection rate frequencies rise dramatically for unexpected accruals when there is no control for external financing, even at low levels of contamination. The abnormal rejection rates persist even when net external financing is used as an additional regressor in the unexpected accruals models. In contrast, when an industry and external-financing matched-firm approach is used, all unexpected accruals models are well-specified.

Consistent with our aim of examining the general effect of net external financing changes on measures of unexpected accruals, we also further decompose (overall) external financing into debt financing and equity financing, given the fact that equity issues occur more rarely (and are smaller in amount) than debt issues over the past 30 years (Eckbo et al. 2007). We find that the presence of large net debt financing is more likely to induce measurement errors in unexpected accruals and bias test of earnings management.

The final step in our analysis is to revisit a recent study that reports evidence of income-decreasing earnings management around share repurchases (Gong et al. 2008). Our evidence suggests that conclusions about the existence of earnings management in this context are not robust to controlling for the problem we have identified. Indeed, when using the matched-firm approach after controlling for the effect on expected accrual of significant net external financing movements, or the McNichols's modification to the Dechow-Dichev model (McNichols 2002), we find no statistically significant evidence of earnings management around open-market repurchase over a similar period to that examined by Gong et al.

Overall, our findings provide evidence that managers' "normal" operating decisions associated with net external financing lead to biased estimates of unexpected accruals 
and potentially erroneous statistical inferences identifying earnings management, even if earnings management is not present. Our research therefore complements recent studies that endeavor to improve the specification of tests of earnings management through the use of statement of cash flow data (Hribar and Collins 2002) and a control for firm performance (Kothari et al. 2005). Our study is also related to prior research that reports a significant relationship between a firm's estimated unexpected accruals and several other firm characteristics, such as growth in long-term earnings (McNichols 2000), fixed asset structure (Young 1999) and changes in a firm's operating environment over its life cycle (Liu 2008). We demonstrate empirically how tests of earnings management can be biased due to a firm's external financing behavior, an event which is by definition associated with changes in net operating assets and expected accruals.

External financing, especially external equity financing, is frequently argued to be one of the major incentives for earnings manipulations (see e.g. Graham et al. 2005). Accordingly, an alternative interpretation of our results is that current period earnings of firms with large external financing cash inflows are systematically managed upwards, while current period earnings of firms with large external financing cash outflows are managed downwards. As it is very difficult to distinguish managed earnings resulting from incentives of current period external financing from the measurement error in unexpected accruals induced by external financing, we cannot entirely rule out this alternative interpretation.

However, given the pervasiveness of external financing activities in the U.S. (especially for external debt financing activities, see Eckbo et al. 2007), our results suggest that caution should prevail in interpreting evidence of earnings management when the identified stimulus is supposed to be uncorrelated (or weakly correlated) with external financing, but the sample contains a significant portion of firms with large net external financing. In such cases, the commonly-used unexpected accruals models are likely to erroneously classify firms with large net external financing as reporting 
nonzero unexpected accruals, and "evidence of earnings management" might simply be due to managers' "normal" operating decisions.

The remainder of this paper is organized as follows. Section 2 explores the relationship between net external financing and accounting accruals through accounting identities, and justifies the importance of controlling for external financing. Sample construction, descriptive statistics and correlation analysis are discussed in Section 3. Section 4 presents the results for tests of bias in earnings management associated with external financing, using simulations to evaluate external financing's influence on statistical inferences of earnings management. The relative importance of debt and equity financing in measurement error is considered in Section 5. Section 6 re-examines evidence of income-decreasing accruals management around share repurchases, and Section 7 concludes.

\section{Motivations}

\subsection{Bias in unexpected accruals calculation}

McNichols and Wilson (1988) and Dechow et al. (1995) suggest that an accrual-based test of earnings management can be interpreted as:

$$
U E X A C^{*}=\beta * P A R T+\varepsilon
$$

where $U E X A C^{*}$ is the true managed (unexpected) accruals, $P A R T$ is a dummy variable that partitions the sample into two groups for which earnings management predictions are specified by the researcher, and $\varepsilon$ a is random accruals error unrelated to the specific earnings management hypothesis. ${ }^{5}$ The true unmanaged (i.e., expected) accruals, $E X A C^{*}$, can be interpreted as:

$$
E X A C^{*}=E X A C+\eta
$$

where $E X A C$ is an estimate of $E X A C^{*}$ obtained by regressing observed accruals on a

\footnotetext{
${ }^{5}$ Note that the intercept term is omitted for notational convenience. In most research contexts, PART will be set equal to one in firm-years during which systematic earnings management is hypothesized (i.e., the event window) and zero during firm-years in which no systematic earnings management is hypothesized (i.e., the estimation window).
} 
vector of variables $(X)$ that are hypothesized to influence $E X A C^{*}$, and $\eta$ is the measurement error reflecting the effect of omitted variables in the estimation of EXAC $^{*}$ as well as idiosyncratic variation. Given the fact that $U E X A C$, the estimate of $U E X A C^{*}$, is equal to accounting accruals minus $E X A C$, the correctly specified model for testing earnings management can be expressed as:

$$
U E X A C=\beta * P A R T+\eta+\varepsilon
$$

As the true unexpected accruals $\left(U E X A C^{*}\right)$ and $\eta$ are unobservable, tests of earnings management are normally characterized by the following regression for UEXAC with $\eta$ omitted:

$$
U E X A C=\hat{\gamma} * P A R T+\varepsilon
$$

where

$$
\hat{\gamma}=\beta+\text { bias }=\beta+\rho(P A R T, \eta) * \frac{\sigma_{\eta}}{\sigma_{P A R T}}
$$

Equation (5) suggests that tests of earnings management can be biased owing to the omission of $\eta$, which captures the effect of the omitted relevant variables in estimating expected accruals. Given a significant and large bias, one could erroneously conclude the existence of earnings management (i.e., observe non-zero values of $\beta$ ), when in fact earnings may not be managed at all (i.e., $\beta=0$ ). In particular, the direction of the bias depends on the sign of the correlation between PART and $\eta$, while the magnitude of bias depends on (1) the correlation between $\eta$ and PART, (2) the standard deviation of $\eta$, and (3) the standard deviation of PART.

\subsection{The relation between external financing and unexpected accruals}

The above analysis suggests that tests of earnings management can be biased if the measurement error in unexpected accruals induced by omitted variables is correlated with the partitioning variable. In this section, we explore the relation between external financing and accounting accruals through accounting identities. 
We start with the balance sheet identity:

$$
\text { Total Assets }=\text { Total Liabilities }+ \text { Owners Equity. }
$$

The most common financial liability is debt $(D)$, while the most common financial asset is the balance of cash and short-term investments $(\mathrm{CASH})$. Distinguishing financial assets and liabilities from operating assets and liabilities gives:

$$
C A S H+\text { Operating Assets }=D+\text { Operating Liabilities }+ \text { Owners Equity. }
$$

We define net operating assets $(N O A)$ as the difference between operating assets and operating liabilities, and denote owners' equity as $E$. Grouping the operating accounts on the left and the financial accounts on the right yields:

$$
N O A=D+E-C A S H .
$$

Note that the NOA expression on the left is the accounting accruals system's estimate of the net value of the firm's operations. We take the first difference of equation (8) (with first difference denoted by $\Delta$ ) and yield:

$$
\triangle N O A=\triangle D+\triangle E-\triangle C A S H \text {. }
$$

We incorporate standard clean surplus assumptions for changes in equity and changes in debt:

$$
\begin{gathered}
\Delta E=I N C O M E+\Delta E Q U I T Y, \\
\Delta D=\text { Interest Expense - Interest Paid }+\triangle D E B T,
\end{gathered}
$$

where INCOME represents net income, $\triangle E Q U I T Y$ is net cash proceeds received from equity holders (equity issuances less dividends and repurchases), $\triangle D E B T$ is net noninterest cash inflow received from to debt holders (debt issuances less debt repayments).

Assuming that interest expense is equal to interest paid, rearrangement gives a simplified representation of equation (9) and (10): 


$$
\triangle N O A=\triangle D E B T+I N C O M E+\triangle E Q U I T Y-\triangle C A S H .
$$

Our measure of net external financing $(\triangle X F I N)$ is the sum of $\triangle D E B T$ and $\triangle E Q U I T Y$. Substituting yields:

$$
\triangle N O A=\triangle X F I N+I N C O M E-\triangle C A S H
$$

The expression $\triangle N O A$ on the left can be considered as a comprehensive measure of total accruals (see e.g. Dechow et al. 2008; Richardson et al. 2005), and decomposed into the changes in current net operating assets $(\triangle C O)$ and the changes in non-current net operating assets $(\triangle N C O)$. The commonly used measure of current accruals $(C A C C)$ and total accruals $(T A C C)$ are thus both part of $\triangle N O A$. Equation (12) also suggests that external financing $(\triangle X F I N)$ and firm performance (INCOME) are two main contributors to changes in net operating assets $(\triangle N O A)$, as evidence by the correlation reported in Dechow et al. (2008, Table 2, p.550) of $\triangle N O A$ with $\triangle X F I N(0.545)$ and INCOME (0.261), these being significantly higher than the correlation with $\triangle C A S H$ (0.003).

Suppose that accruals are decomposed using well-specified accruals expectation models. We then have:

$$
U E X A C^{*}+E X A C^{*}+R E S T \_\triangle N O A=\triangle X F I N+I N C O M E-\triangle C A S H .
$$

where REST_ $\triangle N O A$ represents the remainder of $\triangle N O A$, net of accounting accruals $(C A C C$ or $T A C C)$. In tests of earnings management where the identified stimulus is not supposed to be associated with external financing, we would expect to observe no correlation between the estimates of $U E X A C^{*}$ and $\triangle X F I N$. However, our correlation analysis suggests that, even if there is no systematic earnings management in the sample, we still observe a correlation between the estimated unexpected accruals $(U E X A C)$ and $\triangle X F I N$ (correlation coefficients ranging from 0.05 to 0.21 for different measures of unexpected accruals).

Recall that the true $U E X A C^{*}$ is equal to the estimated $U E X A C$ less the measurement 
error in the estimated expected accruals $(\eta)$. The correlation between $U E X A C$ and $\triangle X F I N$ indicates that some portion of expected accruals is captured by $\eta$, which will bias tests of earnings management. The magnitude of the bias depends not only on the correlation between $\eta$ and the partitioning variable, but also on the standard deviation of $\eta$ and the partitioning variable. Thus, $\triangle X F I N$ is one of the omitted variables that leads to bias in unexpected accruals calculations. In other words, this suggests that a manager's normal expected accruals decisions should be captured not only by the association between accruals and a firm's current period cash flows and near-term changes in revenues (as in commonly used unexpected accruals models), but also by external financing that reflects the firm's investment and operating decisions. ${ }^{6}$

The above analysis is also applicable to the relation between unexpected accruals and firm performance (i.e., INCOME, or alternatively $R O A$ if scaled by total assets). We also observe a significant correlation between estimated UEXAC and INCOME (ranging from 0.17 to 0.43 ), suggesting that firm performance can also bias unexpected accruals calculations. Accordingly, firm performance $(R O A)$ is used as a control when estimating unexpected accruals in recent studies (see e.g. Kothari et al. 2005). Our study thus adds to this strand of literature by investigating the bias which failure to control for external financing causes in tests of earnings management.

Although unexpected accruals proxies (e.g. the Jones model or the modified Jones model) are widely-used in the literature, the potential bias induced by external financing has attracted little attention. One exception is Ball and Shivakumar (2008) who argue that prior evidence of earnings management in IPOs (e.g., Teoh et al. 1998) is unreliable and biased in favour of apparent upward earnings management due to the use of the IPO proceeds. Their analysis sheds light on the channel through which external financing influences current period accruals and its unexpected component.

\footnotetext{
${ }^{6}$ Of course, this analysis is also applicable to the relation between unexpected accruals and firm performance. We observe a correlation between estimated UEXAC and INCOME ranging from 0.17 to 0.43 , consistent with prior evidence that performance can also bias unexpected accrual estimates (Kothari et al. 2005).
} 
Similarly, firms with large external financing cash inflows, either from equity financing or debt financing (or both), tend to expand their operations and investments in fixed assets, accompanied by investments in working capital to support growth. For example, designing, launching, and selling a new product requires a firm to not only build productive capacity through the purchase of fixed assets, but also to manufacture large quantities of inventory to reduce the probability of inventory shortage. Thus, the use of external financing for investments in working capital results in a faster rate of change in working capital than in revenues. As commonly used unexpected accruals models typically assume expected accruals are a function of cash flows from operations and/or changes in revenues, estimates of unexpected accruals from these models can be biased due to external financing and the follow-up investment in net operating assets.

\subsection{Controlling for external financing}

Our analysis suggests the need to control for current period external financing in tests of earnings management. One approach is to expand the set of independent variables in widely-used regression models of expected accruals. In this spirit, we utilize a regression-based approach by augmenting the accruals expectation models to include current period net external financing as an additional regressor. An alternative method is to adjust a firm's unexpected accruals using an industry and $\triangle X F I N$-matched firm approach. In particular, the matched-firm approach adjusts a firm's estimated unexpected accruals by subtracting the corresponding unexpected accruals of a firm matched on the basis of industry and current period $\triangle X F I N$. Such an approach would also mitigate the likelihood that the estimated unexpected accruals are systematically non-zero.

The relative efficacy of the matched-firm approach versus the regression-based approach is ultimately an empirical issue. The regression-based approach imposes stationarity of the relation through time or in the cross-section, and more importantly, 
imposes linearity on the relation between external financing and expected accruals. On the other hand, the matched-firm approach does not impose any particular functional form on the relation between external financing and accruals, but simply assumes homogeneity in the relation between external financing and accruals for the sample and matched firm (i.e., the sample and matched firm, on average, have the similar estimated unexpected accruals that are not attributable to the identified stimulus of earnings management). ${ }^{7}$ Thus, the efficiency of these two approaches depends on how their corresponding assumptions are satisfied in the data. As a result, we examine both approaches in the following and compare their relative efficiency empirically.

\section{Data and descriptive statistics}

\subsection{Sample composition}

The data for this study are obtained from the COMPUSTAT Industrial Annual database for the period 1987-2006, as statement of cash flow data are only available from 1987. Observations are deleted if any of the following conditions are met: (1) Primary industry classification is from the banking, life insurance, or property and casualty insurance industries; (2) Book value of assets is less than \$1 million dollars or missing $;^{8}$ (3) Missing values for sales, or net income before extraordinary items. These restrictions reduce the sample to 136,095 firm-years.

Following Bradshaw et al. (2006), we measure the net amount of cash flow received

\footnotetext{
${ }^{7}$ An important issue associated with the matched-firm approach is whether the use of industry and $\triangle X F I N$-matched control firms removes, in part, unexpected accruals motivated from the identified stimulus of earnings management, and thus reduces the power of tests of earnings management. It is true that matching on external financing by design can and will remove unexpected accruals that are motivated by external financing, thereby generating "abnormal" unexpected accruals rather than "total" unexpected accruals. However, the matching approach is designed to capture the earnings management effect that is beyond that attributable to external financing. If the incentive for earnings management of interest is not supposed to be associated with external financing, the use of $\triangle X F I N$-matched unexpected accruals is appropriate in controlling for the misspecification of the unexpected accruals models associated with external financing.

${ }^{8}$ This ensures that average total assets are greater than $\$ 1$ million to avoid small denominator problems.
} 
from external financing activities $(\triangle X F I N)$ as the sum of $\triangle E Q U I T Y$ and $\triangle D E B T{ }^{9}$ $\triangle E Q U I T Y$ represents net cash received from the sale (and/or purchase) of common and preferred stock less cash dividends paid (COMPUSTAT annual data \#108 less $\# 115$ less \#127). ${ }^{10} \triangle D E B T$ represents net cash received from the issuance (and/or reduction) of debt (COMPUSTAT annual data \#111 less \#114 plus \#301). We require the availability of COMPUSTAT data for each of the above variables, with the exception of Change in Current Debt (COMPUSTAT annual data \#301), which is set to 0 if it is missing. ${ }^{11}$ Bradshaw et al. (2006) find that COMPUSTAT typically backfills data for newly-listed public companies. As a result, $\triangle E Q U I T Y$ primarily reflects both initial public offerings (IPO) and seasoned equity offerings (SEO), while $\triangle D E B T$ includes convertible debt, subordinated debt, notes payable, debentures and capitalized lease obligations. We scale $\triangle X F I N, \triangle E Q U I T Y$ and $\triangle D E B T$ by average total assets (COMPUSTAT item \#6) so as to measure the amount of new financing activity relative to the existing asset base.

As in previous research using financial ratios, we find that the distributions of our scaled financial variables are characterized by a small number of outliers $(2,853$ out of 136,095 firm-years). We thus follow Bradshaw et al. (2006)'s procedure of eliminating observations with an absolute value greater than one. ${ }^{12}$ To examine the robustness of our results, we also employ an alternative measure of $\triangle X F I N$, defined as $\triangle X F I N$ less the changes in cash and cash equivalents (COMPUSTAT annual data \#274). As the results are generally similar, in the following we only report our findings for $\triangle X F I N$.

\footnotetext{
${ }^{9}$ We use the statement of cash flow data to measure external financing variables, because the statement of cash flow data does not suffer from the limitations described for the balance sheet data (Hribar and Collins, 2002).

${ }^{10} \mathrm{We}$ are unable to decompose common and preferred equity from the statement of cash flows, since Compustat does not provide this level of detail.

${ }^{11}$ This is consistent with Bradshaw et al. (2006), who find that the availability of COMPUSTAT annual data \#301 was very limited, in contrast to other variables.

12 This procedure makes sense on a priori grounds, because situations where individual financing components change by more than $100 \%$ of average total assets are clearly unusual cases that we do not want to weight excessively in our analysis. Our results are qualitatively similar if we winsorize the observations, or if we leave them in the analysis.
} 
Finally, following Kothari et al. (2005), we exclude observations if the absolute value of total or current accruals scaled by average total assets exceeds one. Our final sample consists of 131,778 firm-year observations. For these firms we compute total and current unexpected accruals using the modified Jones model (with intercept) (hereafter, denoted UEXAC_MJT and UEXAC_MJC, respectively), unexpected accruals from the Dechow-Dichev (2002) model and McNichols (2002)'s modification to the Dechow-Dichev (2002) model (denoted UEXAC_DD and UEXAC_DDM, respectively), total and current unexpected accruals from the modified Jones model with the intercept and $R O A$ as an additional regressor (denoted $U E X A C_{-} M J T \_R O A$ and UEXAC_MJC_ROA, respectively), and performance-matched total and current unexpected accruals as in Kothari et al. (2005) (denoted UEXAC_PMJT and UEXAC_PMJC, respectively). We use statement of cash flow data to construct total accruals $(T A C C)$ and current accruals $(C A C C)$, as suggested by Hribar and Collins (2002). ${ }^{13}$

To control for net external financing, we utilize two approaches: First, we use a regression-based approach that includes $\triangle X F I N$ as an additional regressor in the above unexpected accruals models. Second, we use a matched-firm approach that adjusts a firm's estimated unexpected accruals by subtracting the corresponding unexpected accruals of a firm matched on the basis of industry and current period $\triangle X F I N$. To mitigate the effect of outliers, we eliminate the top and bottom percentile of variables required as inputs to accruals expectation models, namely total accruals (TACC), current accruals $(C A C C)$, cash flows from operations $(C F O)$, changes in revenues $(\triangle R E V)$, gross property, plant, and equipment $(P P E)$, and return-on-asset $(R O A)$. The Appendix provides a detailed discussion on the estimation of different unexpected accruals measures. Table 1 reconciles the number of observations in the final sample with the data sources noting the effects of the various filters, and Table 2 summarizes the COMPUSTAT items used in defining all variables.

\footnotetext{
${ }^{13}$ Our results remain qualitatively and quantitatively similar when using the balance sheet data as in Kothari et al. (2005).
} 


\section{Table 1 and Table 2 about here}

\subsection{Descriptive statistics}

Table 3 shows descriptive statistics for the unexpected accruals calculations and the external financing variables, as well as other firm characteristics. Note that all variables are scaled by average total assets to reflect their changes relative to the existing asset base, and are reported as percentages. As expected, the mean and the median of the distributions of unexpected accruals are close to zero (by construction), except those for the performance-matched and $\triangle X F I N$-matched unexpected accruals.

We also report univariate statistics for the external financing variables. The positive mean values for $\triangle X F I N, \triangle D E B T$ and $\triangle E Q U I T Y$ of $4.34 \%, 1.37 \%$ and $2.97 \%$, respectively, suggesting an overall tendency towards raising additional external financing. The medians, however, are all close to zero, indicating that the distributions of the three external financing variables are skewed to the right.

When decomposing $\triangle N O A$ into $\triangle X F I N$, net income (INCOME) and $\triangle C A S H$, we find that changes in net operating assets are on average funded by external financing rather than retained earnings, as evidence by a positive mean of $\triangle X F I N(4.34 \%)$ and a negative mean of net income (-2.52\%). However, the standard deviations for $\triangle X F I N$, net income and $\triangle N O A$ are similar, ranging from a low of $16.55 \%$ for $\triangle X F I N$ to a high of $20.05 \%$ for $\triangle N O A$. Thus, changes in net operating assets are dominated by both $\triangle X F I N$ and net income or ROA [as in Kothari et al. (2005)].

\section{Table 3 about here}

\subsection{Correlation analysis and sorting on $\triangle X F I N$}

To determine whether and how strongly the unexpected accruals measures are associated with external financing variables, we present correlations among our 
sample variables in Table 4. ${ }^{14}$ Pearson (Spearman) correlations appear below (above) the diagonal. As a natural consequence of utilizing a large dataset, most of the correlations are statistically significant.

There is a positive correlation between $\triangle X F I N$ and unexpected accruals, indicating that firms with positive net external financing tend to have relatively high unexpected accruals. As expected, we observe a substantial difference between the correlation of unexpected accruals measures (with and without a control for external financing) and $\triangle X F I N$. The Pearson (Spearman) correlations range from 0.05 to 0.21 (from 0.10 to 0.25), in contrast to Pearson and Spearman correlations for those matched on $\triangle X F I N$ that are close to zero.

The correlations of $\triangle X F I N$ and net income with different components of $\triangle N O A$ reveal additional insights on how external financing influences accounting accruals and estimates of unexpected accruals. The Pearson (Spearman) correlation of $\triangle X F I N$ with $\triangle N O A$ is $0.41(0.43)$, higher than that of net income. However, when decomposing $\triangle N O A$ into $\triangle C O$ and $\triangle N C O$, we find that the higher correlation between $\triangle X F I N$ and $\triangle N O A$ is sourced from a higher correlation between $\triangle X F I N$ and $\triangle N C O(0.37$ compared to 0.18 for Pearson correlation, and 0.35 compared to 0.23 for Spearman correlation). These correlations are indicative of financing and operating activities, whereby capital investments in net non-current operating assets are more likely to be funded by external financing than retained earnings.

\section{Table 4 about here}

To enhance our understanding on the relation between $\triangle X F I N$ and unexpected accruals, we first sort firms into quartiles each year based on $\triangle X F I N$, and then report the sample average of all variables for each quartile in Table 5. The results in Table 5

\footnotetext{
${ }^{14}$ For brevity, correlation results for unexpected accrual measures based on current accruals are not presented here, but are available upon request.
} 
confirm a positive correlation between $\triangle X F I N$ and unexpected accruals. In particular, moving from the lower quartile to the upper quartile, we find that unexpected accruals (that fail to control for external financing) increase monotonically. For example, UEXAC_MJT_ROA without controls for $\triangle X F I N$ increases from $-1.40 \%$ of total assets for Quartile 1 to $2.69 \%$ for Quartile 4, while UEXAC_DDM rises from $-0.34 \%$ to $0.45 \%$. When comparing the efficacy of two methods to control for external financing, the matched-firm approach seems to be more efficient because there is no apparent pattern for unexpected accruals across quartiles. UEXAC_MJT_ROA matched on $\triangle X F I N$ is $-0.04 \%$ of total assets for Quartile 1 and $-0.03 \%$ for Quartile 4 , while $U E X A C \_D D M$ is $-0.06 \%$ and $-0.05 \%$, respectively.

\section{Table 5 about here}

Overall, the correlation and sorting results provide evidence that supports a consistent positive relation between $\triangle X F I N$ and unexpected accruals, suggesting that some portion of expected accruals are incorrectly classified as unexpected accruals, leading to bias in tests of earnings management. Although the positive relation is modest and more apparent in the Spearman correlations, the following analysis shows that even modest correlation can lead to significant biases in estimates of unexpected accruals and a high likelihood of erroneous statistical inference in tests of earnings management.

\section{Estimating unexpected accruals and external financing}

\subsection{Estimating the bias in the calculation of unexpected accruals}

The framework proposed by McNichols and Wilson (1988) provides practical guides in estimating the potential impact of mis-specified unexpected accruals in tests of earnings management. By applying the framework in equation (1) through (5), we directly estimate the potential bias arising from a failure to control for $\triangle X F I N$. There are at least two partitions that are potentially correlated with this measurement error: 
$\mathrm{PART}_{\triangle \mathrm{XFIN}>\mathrm{Q} 3}$ and $\mathrm{PART}_{\triangle \mathrm{XFIN}<\mathrm{Q} 1}$. In particular, we define $\mathrm{PART}_{\triangle \mathrm{XFIN}>\mathrm{Q} 3}$ as a dummy variable taking value of 1 when the firm's $\triangle X F I N$ is higher than the $75^{\text {th }}$ percentile of the distribution in the corresponding year, and zero otherwise. Similarly, $\mathrm{PART}_{\triangle \mathrm{XFIN}<\mathrm{Q} 1}$ is a dummy variable set equal to 1 if the firm's $\triangle X F I N$ is lower than the $25^{\text {th }}$ percentile of the distribution on a yearly basis, and zero otherwise.

Table 6 provides evidence of the bias in tests of earnings management that arise when the partitioning variable coincides with each of these two partitions. The measurement error, $\eta$, is the difference between the unexpected accruals measures with and without a control for external financing. Take UEXAC_MJT as an example. Under the assumption that the modified Jones model with $\triangle X F I N$ as an additional regressor is correctly specified, $\eta$ is measured as the difference between UEXAC_MJT estimated from the original modified Jones model and the estimate from the modified Jones model with $\triangle X F I N$ as an additional regressor. Panel A of Table 6 shows the estimated bias if the unexpected accruals matched on $\triangle X F I N$ are expected to be correctly specified. As shown in the second column of Panel A, the bias associated with $\mathrm{PART}_{\triangle \mathrm{XFIN}>\mathrm{Q} 3}$ ranges from $0.53 \%$ of total assets for $U E X A C_{-} D D M$ to $3.53 \%$ for UEXAC_MJT_ROA. This is adjudged as economically significant given that the median accounting earnings of the sample is $1.7 \%$ of total assets. The bias associated with $\mathrm{PART}_{\triangle \mathrm{XFIN}<\mathrm{Q} 1}$ is smaller in magnitude but of opposite direction, ranging from $-0.51 \%$ for UEXAC_DDM to $-3.14 \%$ for UEXAC_MJT_ROA. Panel B reports that the unexpected accruals models that include $\triangle X F I N$ as a control procedure are well-specified. In general, the estimated biases associated with both $\mathrm{PART}_{\triangle \mathrm{XFIN}>\mathrm{Q} 3}$ and $\mathrm{PART}_{\triangle \mathrm{XFIN}<\mathrm{Q} 1}$ are smaller in magnitude than those in Panel A.

\section{Table 6 about here}

The above analysis provides evidence of a significant bias in unexpected accruals estimation. It, however, does not provide direct evidence of the potential impact on 
statistical inferences. To address this issue, we examine if statistical inferences change due to measurement error sourced from $\triangle X F I N$. Specially, unexpected accruals are regressed on each of the two partitioning variables on a yearly basis. Table 7 reports the sample average of the 20 individual-year parameter estimates and its significance across all years. If the unexpected accruals models are correctly specified, we would expect the coefficients on PART to be insignificantly different from zero, given that there is no obvious reason for the existence of significant earnings management associated with either of the two partitions for such a large sample.

The results in Table 7 support our conjecture that statistical inference in tests of earnings management hinge on whether or not a control for $\triangle X F I N$ is included. Specifically, the second column of Panel A demonstrates that firms with large external financing cash inflows tend to exhibit evidence of significant income increasing earnings management, while firms with large external financing cash outflows tend to be classified as income decreasing earnings managers, even if earnings management does not actually exist. The estimated coefficients on $\mathrm{PART}_{\triangle \mathrm{XFIN}>\mathrm{Q} 3}$ range from $0.63 \%$ to $3.70 \%$, and have significant t-statistics at the $1 \%$ level (ranging from 4.7 to 13.8 ). The estimated coefficients on $\operatorname{PART}_{\triangle \mathrm{XFIN}<\mathrm{Q} 1}$ are similar in magnitude but of the opposite direction, with even more significant t-statistics. When we control for $\triangle X F I N$ by using either the regression-based approach or the matched-firm approach, the same partition shows less significant (or even insignificant) bias in testing earnings management. In particular, results in Panel $\mathrm{C}$ for the regression-based approach demonstrate that the estimated coefficients on both $\mathrm{PART}_{\triangle \mathrm{XFIN}>\mathrm{Q} 3}$ and $\mathrm{PART}_{\triangle \mathrm{XFIN}<\mathrm{Q} 1}$ reduce substantially in magnitude, but are still statistically significant. When matching on $\triangle X F I N$, the results in Panel B show that the estimated coefficients on both $\mathrm{PART}_{\triangle \mathrm{XFIN}>\mathrm{Q} 3}$ and $\mathrm{PART}_{\triangle \mathrm{XFIN}<\mathrm{Q} 1}$ are economically and statistically insignificant, ranging from $-0.21 \%$ to $0.27 \%$.

\section{Table 7 about here}




\subsection{Simulation analysis}

The results in Table 7 assume a 100\% overlap between the partitioning variable used in tests of earnings management and large net external financing (either $\mathrm{PART}_{\triangle \mathrm{XFIN}>\mathrm{Q} 3}$ or $\left.\mathrm{PART}_{\triangle \mathrm{XFIN}<\mathrm{Q} 1}\right)$. However, the partitioning variable chosen by the researcher rarely overlaps perfectly. Rather, the sample is often only partially contaminated by firms with large net external financing, and the degree of contamination varies depending on the identified stimulus for earnings management. Accordingly, we conduct simulations to estimate the potential bias in tests of earnings management where the partitioning variable is imperfectly correlated with net external financing.

Our simulation procedure follows Hribar and Collins (2002). In particular, we start by taking a random sample of 1,000 firms without replacement from the subsample of firms that are not involved in large net external financing (i.e., firms with both $\mathrm{PART}_{\triangle \mathrm{XFIN}>\mathrm{Q} 3}$ and $\mathrm{PART}_{\triangle \mathrm{XFIN}<\mathrm{Q} 1}$ equal to 0 ). This is referred to as our $0 \%$ contamination sample. Using 250 iterations of this procedure, we calculate bias in tests of earnings management (as a percentage of total assets) as in Equation (5), the difference between unexpected accruals estimated from models without and with controlling for $\triangle X F I N$ (i.e., $\eta$ as in Equation (5)), and the probability of committing a type I error if there is no earnings management present. Based on 250 trials, we compute the rejection frequencies (i.e., type I error rates) at the $5 \%$ and $1 \%$ significance levels for a one tailed t-test, together with the sample average of the estimated biases and differences. Next, we increase the percent contaminated to $10 \%$ by taking a random sample of 100 firms without replacement from the subsample of firms with large net external financing (i.e., firms with $\mathrm{PART}_{\triangle \mathrm{XFIN}>\mathrm{Q} 3}=1$ for tests of $\mathrm{PART}_{\triangle \mathrm{XFIN}>\mathrm{Q} 3}$, and firms with $\mathrm{PART}_{\triangle \mathrm{XFIN}<\mathrm{Q} 1}=1$ for tests of $\mathrm{PART}_{\triangle \mathrm{XFIN}<\mathrm{Q} 1}$ ) and a random sample of 900 firms without replacement from the subsample of firms with moderate $\triangle X F I N$. We repeat this procedure 250 times, and measure the bias and rejection frequency at the $10 \%$ level of contamination. We continue this procedure until the percent of the sample contaminated by firms with large external financing cash inflows or outflows is $100 \%$. 
The estimation bias associated with $\mathrm{PART}_{\triangle \mathrm{XFIN}>\mathrm{Q} 3}$ and $\mathrm{PART}_{\triangle \mathrm{XFIN}<\mathrm{Q} 1}$ at different contamination levels are reported in Panel A and Panel B of Table 8 (A1 and B1 for $\mathrm{PART}_{\triangle \mathrm{XFIN}>\mathrm{Q} 3}$, and A2 and B2 for $\left.\mathrm{PART}_{\triangle \mathrm{XFIN}<\mathrm{Q} 1}\right)$. Generally, the biases are found to be smaller in magnitude for the contaminated sample, relative to the biases for the whole sample in Table 6. For example, when the unexpected accruals with $\triangle X F I N$ as an additional regressor are expected to be well-specified, the bias associated with $\mathrm{PART}_{\triangle \mathrm{XFIN}>\mathrm{Q} 3}($ Panel B1 of Table 8) average about $0.86 \%$ for UEXAC_MJT, 2.89\% for UEXAC_MJT_ROA, $0.69 \%$ for UEXAC_PMJT, $1.24 \%$ for UEXAC_DD and $0.27 \%$ for $U E X A C \_D D M$, with low fluctuation across different contamination levels. However, the estimation biases associated with both $\mathrm{PART}_{\triangle \mathrm{XFIN}>\mathrm{Q} 3}$ and $\mathrm{PART}_{\triangle \mathrm{XFIN}<\mathrm{Q} 1}$ are still economically significant for those contaminated samples. On the other hand, as the contamination level increases, the differences between unexpected accruals with and without a control for $\triangle X F I N$ increase monotonically for $\mathrm{PART}_{\triangle \mathrm{XFIN}>\mathrm{Q} 3}$ and decrease for $\mathrm{PART}_{\triangle \mathrm{XFIN}<\mathrm{Q} 1}$ (see Panel $\mathrm{C}$ and Panel D of Table 8). For example, the difference of UEXAC_MJT assuming unexpected accruals matched on $\triangle X F I N$ is the true model (i.e., UEXAC_MJT in Panel C1) increases from $0.47 \%$ of total assets for the $10 \%$ contamination level to $1.16 \%$ for the $90 \%$ contaminated sample, when testing the simulated sample with net external financing inflows (i.e., testing $\operatorname{PART}_{\triangle \mathrm{XFIN}>\mathrm{Q} 3}$ ). However, the difference of UEXAC_MJT reduces from $0.21 \%$ for $10 \%$ contamination to $-1.12 \%$ for $90 \%$ contamination level, when the simulated sample is contaminated by firms with net external financing outflows (see Panel C2 of Table 8).

\section{Table 8 about here}

Results of the probability of committing a type I error for $\mathrm{PART}_{\triangle \mathrm{XFIN}>\mathrm{Q} 3}$ and $\mathrm{PART}_{\triangle \mathrm{XFIN}<\mathrm{Q} 1}$ are tabulated in Table 9 and Table 10. Because the results for the $1 \%$ significance level are generally similar to those for the 5\% significant level, we only discuss the $5 \%$ results in Table 9. 


\section{Table 9 and Table 10 about here}

We first look at the results for $\mathrm{PART}_{\triangle \mathrm{XFIN}>\mathrm{Q} 3}$ without a control for $\triangle X F I N$ (see Panel A of Table 9). At the $0 \%$ contamination level, all unexpected accruals models are relatively well-specified, with the empirical rejection frequencies ranging from $2.0 \%$ to $8.0 \%$. However, as the percent of the sample contaminated rises, the probability of committing a type I error increases dramatically for all models, except the Dechow-Dichev model and the McNichols's modification to the Dechow-Dichev model. For example, even when the sample is only $30 \%$ contaminated, the probabilities of committing type I errors in the absence of earnings management are over $60 \%$, in contrast to the expected level under the null of $5 \%$. Moreover, when the percent of the sample contaminated by firms with large $\triangle X F I N$ rises to $40 \%$, the type I error rates increase to $68 \%$ for $U E X A C \_M J T, 99 \%$ for $U E X A C \_M J T \_R O A, 78 \%$ for UEXAC_PMJT, 92\% for UEXAC_MJC, 98\% for UEXAC_MJC_ROA, and 86\% for UEXAC_PMJC, respectively. Thus, at contamination levels of $40 \%$ and greater, one would be likely to conclude that earnings had indeed been manipulated, even if earnings management is not present. It is also noteworthy that among the eight unexpected accruals models, the McNichols's modification to the Dechow-Dichev model is relatively well-specified in terms of lower rejection frequencies for different levels of contamination. For example, when the sample is $40 \%$ contaminated, the probabilities of committing type I errors is 33\%. Even if there is a $100 \%$ overlap between the partitioning variable and $\mathrm{PART}_{\triangle \mathrm{XFIN}>\mathrm{Q} 3}$, the type I error rate is $67 \%$, in contrast to nearly $100 \%$ for other models.

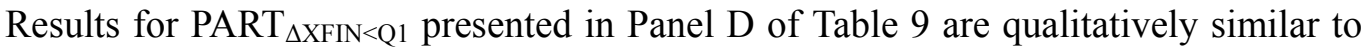
those in Panel A. At the $0 \%$ contamination level, the probabilities of committing type I errors ranges from $2 \%$ to $21 \%$, indicating that all the models are relatively well-specified except UEXAC_MJC_ROA and UEXAC_DD. As the level of contamination in the sample increases, the rejection frequencies increase accordingly, although not as quickly as they do for $\mathrm{PART}_{\triangle \mathrm{XFIN}>\mathrm{Q} 3}$. For example, at the $30 \%$ 
contamination level, the type I error rates for most unexpected accruals models (except $U E X A C_{-} M J T$ and $U E X A C_{-} D D M$ ) are over $50 \%$, in contrast to the expected $5 \%$. Consistent with results for $\mathrm{PART}_{\triangle \mathrm{XFIN}>\mathrm{Q} 3}$, the McNichols's modification to the Dechow-Dichev model is relatively well-specified, with a lower type I error rate of $8.8 \%$ at the $30 \%$ contamination level. Overall, results for unexpected accruals models without a control for $\triangle X F I N$ suggest that even a modest level of contamination by firms with large net external financing can have a potentially large impact on the statistical inferences that are drawn on the existence of earnings management.

When we control for $\triangle X F I N$ by using a matched-firm procedure, all unexpected accruals models become well-specified at any contamination level (see Panel B and Panel E of Table 9). For example, the type I error rates are ranging from $2.0 \%$ to $5.2 \%$ for $\mathrm{PART}_{\triangle \mathrm{XFIN}>\mathrm{Q} 3}$, and from $4.8 \%$ to $7.6 \%$ for $\mathrm{PART}_{\triangle \mathrm{XFIN}<\mathrm{Q} 1}$, even the sample is $100 \%$ contaminated.

However, the regression-based approach that includes $\triangle X F I N$ as an additional regressor in unexpected accruals models is insufficient to mitigate the potential bias from $\triangle X F I N$ in tests of earnings management. Results for $\mathrm{PART}_{\triangle \mathrm{XFIN}>\mathrm{Q} 3}$ in Panel $\mathrm{C}$ of Table 9 show that all the models are mis-specified at almost any level of contamination, with significantly higher type I errors than the expected level of $5 \%$. For example, when the sample is not contaminated, the type I error rates are $28.4 \%$ for UEXAC_MJT, $44.8 \%$ for UEXAC_MJT_ROA, 21.2\% for UEXAC_MJC, $16 \%$ for UEXAC_PMJC, and $8.8 \%$ for UEXAC_DDM. On the other hand, results for $\mathrm{PART}_{\triangle \mathrm{XFIN}<\mathrm{Q} 1}$ demonstrate that, compared to results without controlling for $\triangle X F I N$, the rejection frequencies reduce slightly; but one would still be likely to reject the null of no earnings management even in the absence of earnings manipulation.

\section{Debt financing versus equity financing}

Eckbo et al. (2007) study the aggregate debt and equity issuance activity in the U.S. 
during the period 1980-2003, with a population of 83,282 issues. In particular, they find that straight debt offerings outnumber SEOs by approximately three to one $(37,298$ vs. 11,151), and the typical public debt issue is about three times as large as the average SEO ( $\$ 230$ versus $\$ 86$ million). They thus suggest that, consistent with the early finding of Mikkelson and Partch (1986), equity issues are rarer in issuance frequency and smaller in amount than debt issues.

Our analysis above suggests that the presence of large net (overall) external financing $(\triangle X F I N)$ tends to induce measurement errors in unexpected accruals and biased tests of earnings management. Given the pervasiveness of external debt issuance, a natural question is whether such measurement errors are more likely caused by net debt financing $(\triangle D E B T)$ or net equity financing $(\triangle E Q U I T Y)$. To investigate the relative importance of debt and equity financing, we examine how the statistical inferences on earnings management change due to measurement error from $\triangle D E B T$ and $\triangle E Q U I T Y$. In particular, we regress unexpected accruals on the partitioning variables based on $\triangle D E B T$ and $\triangle E Q U I T Y$ each year, and report the sample average and significance of the 20 individual-year parameter estimates in Table 11.

\section{Table 11 about here}

The results in Table 11 still support our findings that firms with large external financing cash inflows (outflows) tend to be classified as income increasing (decreasing) earnings managers, regardless of whether their financing is via debt or equity. For example, all estimated coefficients on both $\mathrm{PART}_{\triangle \mathrm{DEBT}>\mathrm{Q} 3}$ and $\mathrm{PART}_{\triangle \mathrm{DEBT}<\mathrm{Q} 1}$ are statistically significant at $1 \%$ level except $U E X A C_{-} D D M$ for $\mathrm{PART}_{\triangle \mathrm{DEBT}<\mathrm{Q} 1}$, with economically significant estimation errors ranging from $-0.36 \%$ to $3.25 \%$ of total assets. The evidence for equity financing is weaker, but most estimated coefficients on both $\mathrm{PART}_{\triangle \mathrm{EQUITY}>\mathrm{Q} 3}$ and $\mathrm{PART}_{\triangle \mathrm{EQUITY}<\mathrm{Q} 1}$ are still statistically significant, though with smaller magnitudes relative to debt financing. Overall, the results suggest that unexpected accruals estimates for firms with large net 
debt financing are more likely to contain measurement errors and bias tests of earnings management than firms with large equity financing.

\section{Unexpected accruals around share repurchases}

The results of the previous sections suggest that estimated unexpected accruals exhibit a bias that is related to a firm's external financing behaviour, and this bias could lead the researcher to conclude that significant earnings management exists, when in fact there is none. This bias is also more likely to occur for firms with large net debt financing cash flows, in contrast to firms with large net equity financing cash flows.

To provide further insights on how controlling for external financing is likely to change empirical inferences, we re-examine the evidence of income-decreasing earnings management around share repurchases. Gong et al. (2008) report significant negative unexpected accruals around open-market repurchases. However, managers' "normal" operating and financing decisions associated with the reduction of debt levels (i.e., net debt financing cash outflows) could also lead to negatively biased estimates of unexpected accruals, and these firms can exhibit a pattern of unexpected accruals that is likely to be similar to firms making share repurchases.

We identify open-market repurchases for 1988-2002 from the Security Data Company's (SDC) Mergers and Acquisitions database. Following Gong et al. (2008), we utilize a conditional procedure to identify repurchase announcements. In particular, conditional on an share repurchase announcement appearing in SDC, we require the dollar value of actual repurchases in a given fiscal year based on Compustat annual data item \#115 (Purchases of Common and Preferred Stock) to exceed 1\% of the firm's market value. ${ }^{15}$ We also exclude block-repurchases and self-tender offers. The

\footnotetext{
${ }^{15}$ We combine the two data sources (SDC and Compustat) because, on the one hand, SDC generally codes a repurchase as complete only after the firm essentially repurchases all the shares that it intended to repurchase. Therefore, partial repurchases are generally coded as pending and the number of shares repurchased is not reported. On the other hand, Compustat annual data item \#115 is an aggregation of many other types of transactions besides open-market repurchases, including conversions of other
} 
final sample has 1,050 open-market repurchase announcements that are followed by actual repurchases during the year of the repurchase announcement. ${ }^{16}$ We re-examine tests of income-decreasing earnings management for firms making open-market repurchases, and then we show how controlling for the firm's external financing is likely to change inferences.

We begin our re-examination by first calculating mean unexpected accruals around open-market repurchases without considering external financing. We calculate the several different unexpected accruals estimates as used in our tests above, and present the results in Table 12. We find that on average, repurchase firms report significantly negative unexpected for UEXAC_MJT and UEXAC_PMJT accruals representing $0.57 \%$ and $1.08 \%$ of total assets respectively (with a robust $t$-statistic of -2.24 and -3.35 respectively), confirming those reported in Gong et al. (2008). ${ }^{17}$

\section{Table 12 about here}

Grullon and Michaely (2004) document that a typical repurchasing firm has ample cash reserves prior to open-market repurchases, suggesting that managerial decision on net debt financing is not supposed to be relevant to the decision on share repurchases. We sort the repurchase sample according to net external debt financing ( $\Delta$ Debt) based on the quartile breakpoints of the whole Compustat sample, and re-calculate the average unexpected accruals within each group. The pattern of unexpected accruals for repurchase firms shows that negative unexpected accruals are concentrated among firms in the quartile 1 and quartile 2, which are characterized as firms with net debt financing cash outflows. Take UEXAC_MJT as an example. The

classes of stock into common stock, purchases of treasury stock, retirements of common or preferred stock, and redemptions of redeemable preferred stock. Thus, Compustat data item \#115 may have a positive value even when no open-market repurchase occurs. Our conditional procedure is utilized to reduce the noise associated with using Compustat data item \#115 to estimate actual repurchases.

${ }^{16}$ We find our results for unexpected accruals on a yearly basis are qualitatively and quantitatively comparable to those reported in Gong et al. (2008) who use quarterly data.

${ }^{17}$ Gong et al. (2008) report negative unexpected accruals consisting of $0.57 \%$ of total assets for unexpected accruals based on the modified Jones model (see p.960 of Gong et al. (2008) in Panel A of Table II). 
1,050 repurchase firms are equally distributed across quartiles, indicating the contamination level of net debt financing outflow is about $25 \%$. There are 232 and 268 observations in quartile 1 and quartile 2 respectively, representing about $50 \%$ of the whole sample. Repurchase firms in quartile 1 and quartile 2 report significantly negative unexpected accruals of $-1.85 \%$ and $-1.17 \%$, with robust $t$-statistics of -3.01 and -2.50 respectively. In contrast, firms in quartile 4 with large external debt financing cash inflows are found to exhibit income-increasing earnings management. These findings show that managers of repurchase firms with net debt financing inflow do not appear to engage in income-decreasing earnings management concurrent with repurchase announcement.

To further investigate this issue, we estimated UEXAC_ $\triangle D e b t\left(U E X A C_{-} \triangle X F I N\right)$ by using a matching procedure based on industry and net external debt (overall) financing for UEXAC_MJT. We found that after controlling for external financing, the unexpected accruals for $U E X A C_{-} D D M, U E X A C_{-} \triangle D e b t$ and UEXAC_ $\triangle X F I N$ are not significantly different from zero for the whole sample and across quartiles. In particular, the average unexpected accruals for UEXAC_ $\triangle D e b t$ is $0.57 \%$ of total assets for the whole sample and ranges from $-0.28 \%$ to $1.11 \%$ across quartiles, all of which have insignificant $t$-statistics.

Thus, although researchers might conclude based on the first two columns of Table 12 Panel A that the average firm records negative unexpected accruals concurrent with open-market repurchases, Panel B reveals that these findings hold only for firms with net external debt financing cash outflows. The overall results in Table 12 show that managers' "normal" operating and financing operations, not necessarily the share repurchase event itself, can lead to a negative bias in unexpected accruals.

\section{Conclusion}

Most research in the earnings management literature requires a proxy for managed 
earnings. This paper explores the notion that the widely-used unexpected accruals measures suffer from specification errors, when the sample contains firms with large net external financing. In particular, this study examines the potential bias in estimates of unexpected accruals arising from external financing and its impact on statistical inferences in identifying earnings management.

After exploring the positive relation between accounting accruals and external financing through accounting identities, we first provide evidence on the correlation between estimates of unexpected accruals and external financing, suggesting the existence of measurement errors in unexpected accruals sourced from external financing. We then demonstrate that unexpected accruals from different accruals expectation models are considerably biased upwards for firms with large external financing cash inflows, and biased downwards for firms with large cash outflows. The simulations show that even a modest proportion of firms with large net external financing in the sample dramatically inflate rejection rates for tests at the $5 \%$ and $1 \%$ significance level. The regression-based approach that includes the external financing variable as an additional regressor does not improve the test specification, while the use of the matched-firm procedure based upon industry and external financing generates well-specified type I error rates. Overall, our results show that failure to control for external financing causes biased estimates of unexpected accruals, and could lead to the erroneous conclusion that significant earnings management exists when in fact there is none.

Our findings have implications for studies designed to detect earnings management and the estimation of unexpected and expected accruals. This is especially pertinent in cases where the partitioning variable used to identify instances of earnings management is supposed to be uncorrelated with external financing, when in fact the two are correlated. Our results suggest that it would be prudent for researchers to consider the relation between the partitioning variable and external financing, and underscore the importance of additional tests to control for possible errors in 
unexpected accruals measurement introduced by external financing. This can be achieved by examining the robustness of results for a sub-sample of firms that are not involved in net external financing activities or using the matched-firm approach based on industry and external financing. 


\section{Appendix: Unexpected accruals models}

\section{A.1 The Modified-Jones Model}

Jones (1991) assumes that expected accruals depend on accounting (economic) fundamentals like the change in revenues and the level of property, plant, and equipment. The Jones model for expected accruals can be stated as:

$$
\frac{T A C C_{i t}}{A T A_{i, t-1}}=k_{1 t} \frac{1}{A T A_{i, t-1}}+k_{2} \frac{\Delta R E V_{i t}}{A T A_{i, t-1}}+k_{3} \frac{P P E_{i t}}{A T A_{i, t-1}}+\varepsilon_{i t}
$$

where $T A C C_{i, t-1}, A T A_{i, t-1}$ are firm $i$ 's total accruals and average total assets for year $t-1$, $\triangle R E V_{i, t}$ is the change in firm $i$ 's revenues between year $t-1$ and $\mathrm{t}$ and $P P E_{i t}$ is the gross value of property, plant and equipment for firm $i$ in year $t$. Once the model is estimated (either in time-series or cross-sectionally), the fitted values are used as estimated expected accruals, and the residuals are considered as unexpected accruals.

The original Jones model implicitly assumes that discretion is not exercised over revenue in either the estimation period or the event period, the resulting measure of unexpected accruals does not reflect the impact of sales-based manipulation. In an attempt to capture earnings manipulation over revenue recognition, Dechow et al. (1995) modify the Jones procedure by subtracting the change in receivables $(\triangle R E C)$ from $\triangle R E V$ for each sample firm. The modified Jones model for expected accruals is:

$$
E X A C_{i t}=\hat{k}_{1 t} \frac{1}{A_{i, t-1}}+\hat{k}_{2} \frac{\left(\Delta R E V_{i t}-\Delta R E C_{i t}\right)}{A_{i, t-1}}+\hat{k}_{3} \frac{P P E_{i t}}{A_{i, t-1}}
$$

Where $\triangle R E C_{i t}$ is the change in accounts receivable between year $\mathrm{t}-1$ and $\mathrm{t}$ for firm $\mathrm{i}$. The coefficient estimates from equation (A1) are used as inputs of (A2) to estimate the expected accruals $\left(E X A C_{i t}\right)$ in (A2). Unexpected accruals (UEXAC) are thus defined as the difference between total accruals and the estimated expected accruals from (A2).

\section{A.2 The Dechow-Dichev (2002) model and the McNichols (2002)'s modifications}

The Dechow-Dichev approach is based on the intuition that accruals are temporary 
adjustments that resolve timing problems in the underlying cash flows at the cost of making assumptions and estimates. Precise estimates imply a good match between current accruals and past, present, and future cash flow realizations, while imprecise or erroneous estimates reduce the beneficial role of accruals. Thus, Dechow and Dichev (2002) define accruals quality as the extent to which accruals map into cash flow realizations, and enumerate this notion of accruals quality as the standard deviation of the residuals from firm-specific regressions of working capital accruals on last-year, current, and one-year-ahead cash flows from operations. In particular, Dechow and Dichev (2002) estimate the following firm-level time-series regression:

$$
\Delta W C_{i, t}=\beta_{0}+\beta_{1} C F O_{i, t-1}+\beta_{2} C F O_{i, t}+\beta_{3} C F O_{i, t+1}+\varepsilon_{i, t}
$$

where $\triangle W C$ is the change in working capital from year $t-1$ to year $t$. All variables in the model are deflated by average total assets. The residuals from equation (A3) can be considered as unexpected accruals.

One important feature of the Dechow-Dichev approach is that the notion of accruals estimation errors includes both intentional and unintentional errors. Intentional estimation error arises from incentives to manage earnings, while unintentional error arises from management lapses and environmental uncertainty. However, the Dechow-Dichev measure of unexpected accruals is affected by the measurement error in accruals, regardless of management intent. McNichols (2002) links Dechow and Dichev (2002)'s framework to the Jones-type approach, by modelling intentional estimation error arises from incentives to manage earnings. In particular, the McNichols (2002)'s modification of the Dechow-Dichev model is as follows:

$$
\Delta W C_{i, t}=\beta_{0}+\beta_{1} C F O_{i, t-1}+\beta_{2} C F O_{i, t}+\beta_{3} C F O_{i, t+1}+\beta_{4} \Delta R E V_{i, t}+\beta_{5} P P E_{i, t}+\varepsilon_{i, t}
$$

All variables are deflated by average total assets, and the residuals from the estimated model are used as a measure of unexpected accrual. McNichols (2002) demonstrates that including sales in the Dechow-Dichev model provides a better measure of unexpected accruals with controlling for measurement error in cash flow variables, and provide evidence on the validity of the modification. 


\section{A.3 Controlling for firm performance}

Kothari et al. (2005) argue that accruals of firms that have experienced unusual performance are expected to be systematically non-zero and therefore, firm performance is correlated with total and unexpected accruals. Kothari et al. (2005) thus propose two ways to control for firm performance in estimating unexpected accruals. The first approach uses performance variables, such as return-on-asset $(R O A)$, as an additional independent variable in the modified Jones model. Therefore, the modified Jones model with $R O A$ for expected accruals is:

$$
\frac{T A_{i t}}{A_{i, t-1}}=k_{1 t} \frac{1}{A_{i, t-1}}+k_{2} \frac{\left(\Delta R E V_{i t}-\Delta R E C_{i t}\right)}{A_{i, t-1}}+k_{3} \frac{P P E_{i t}}{A_{i, t-1}}+k_{4} \frac{R O A_{i t}}{A_{i, t-1}}+\varepsilon_{i t}
$$

where all variables are the same as defined before.

The alternative approach Kothari et al. (2005) propose is based on a performance-matched procedure. unexpected accruals matched on firm performance can be calculated by first matching the firm-year observation of the sample firm with the firm-year observation for the control firm with the closest $R O A$ and from the same industry group. Then, unexpected current accruals for each of the sample firms are estimated as well as the matched firms. Abnormal current accruals are thus defined as the difference between the unexpected current accruals of the sample firm and the unexpected current accruals of its matched firm. Specially, the performance-matched approach for unexpected accruals can be written as:

$$
U E X A C^{\prime}{ }_{i t}=U E X A C_{i t}-\mathrm{UEXAC}_{\mathrm{jt}} .
$$

where $U E X A C_{i}$ and $U E X A C_{j}$ are unexpected accruals of the sample firm $i$ and the control firm $j$ estimated from the modified Jones model. UEXAC' is the measure of the performance-matched unexpected accruals. Kothari et al. (2005) find that matching based on the current year $R O A$ performs better than matching on the prior year $R O A$ and the performance-matched approach is superior to the way by including ROA in the unexpected accruals models. 


\section{References}

Ball, R., and Shivakumar, L., 2006, The role of accruals in asymmetrically timely gain and loss recognition, Journal of Accounting Research 44, 207-242.

Ball, R., and Shivakumar, L., 2008, Earnings quality at initial public offerings, Journal of Accounting and Economics 45, 324-349.

Bradshaw, M., Richardson, S., and Sloan, R., 2006, The relation between corporate financing activities, analysts' forecasts and stock returns, Journal of Accounting and Economics 42, 53-85.

Dechow, P., and Dichev, I., 2002, The quality of accruals and earnings: The role of accrual estimation errors, The Accounting Review 77, 35-59.

Dechow, P., Richardson, S.A., and Sloan, R., 2008, The persistence and pricing of the cash component of earnings, Journal of Accounting Research 46, 537-566.

Dechow, P., Sloan, R., and Sweeney, A., 1995, Detecting earnings management, The Accounting Review 70, 193-225.

Eckbo, B.S., Masulis, R.W., and Norli, O., 2007, Security offerings, Handbook of Corporate Finance: Empirical Corporate Finance, Volume 1 Chapter 6, North-Holland/Elsevier.

Fields, T., Lys, T., and Vincent, L., 2001, Empirical research on accounting choice, Journal of Accounting and Economics 31, 255-307.

Graham, J., Harvey, C., and Rajgopal, S., 2005, The economic implications of corporate financial reporting, Journal of Accounting and Economics 40, 3-73.

Gong, G., Louis, H., and Sun, A.X., 2008, Earnings management and firm performance following open-market repurchases, The Journal of Finance 63, 947-986.

Grullon, G., and Michaely, R., The information content of share repurchase programs, The Journal of Finance 59, 651-680.

Hribar, P., and Collins, D., 2002, Errors in estimating accruals: Implications for empirical research, Journal of Accounting Research 40, 105-134.

Hribar, P., and Nichols, D.C., 2007, The use of unsigned earnings quality measures in tests of earnings management, Journal of Accounting Research 45, 1017-1053.

Jones, J., 1991, Earnings management during import relief investigations, Journal of Accounting Research 29, 193-228.

Kothari, S.P., 2001, Capital markets research in accounting, Journal of Accounting and Economics 31, 105-231.

Kothari, S.P., Leone, A., and Wasley, C., 2005, Performance matched discretionary accrual measures, Journal of Accounting and Economics 39, 163-197.

Leary, M.T., and Roberts, M.R., 2005, Do firms rebalance their capital structures? The Journal of Finance 60, 2575-2619.

Liu, M., 2008, Accruals and managerial operating decisions over the firm life cycle, Working paper, Pennsylvania State University.

McNichols, M., 2000, Research design issues in earnings management studies, Journal of Accounting and Public Policy 19, 313-345. 
McNichols, M., 2002, Discussion of the quality of accruals and earnings: The role of accrual estimation errors, The Accounting Review 77, 61-69.

McNichols, M., and Wilson, G.., 1988, Evidence of earnings management from the provision of bad debts, Journal of Accounting Research 26, 1-31.

Mikkelson, W.H., and Partch, M.M., 1986, Valuation effects of security offerings and the issuance process, Journal of Financial Economics 15, 30-60.

Richardson, S.A., Sloan, S., Soliman, M., and Tuna, I., 2005, Accrual reliability, earnings persistence and stock prices, Journal of Accounting and Economics 39, 437-485.

Shivakumar, L., 2000, Do firms mislead investors by overstating earnings before seasoned equity offerings, Journal of Accounting and Economics 29, 339-371.

Teoh, S.H., Welch, I., and Wong, T.J., 1998, Earnings management and the long-term market performance of initial public offerings, The Journal of Finance 53, 1935-1974.

Young, S., 1999, Systematic measurement error in the estimation of discretionary accruals: An evaluation of alternative modelling procedures, Journal of Business Finance \& Accounting 26, 833-862. 


\section{Table 1: The number of observations with various filters}

This Table reconciles the number of observations in the final sample with the data sources and the various filters.

\begin{tabular}{llc}
\hline Step & Filters & $\begin{array}{l}\text { Number of } \\
\text { observations }\end{array}$ \\
\hline 1 & Firm-year observations on COMPUSTAT for 1987 to 2006 & 456,944 \\
2 & $\begin{array}{l}\text { Firm-year observations after deleting primary industry classification from } \\
\text { the banking, life insurance, or property and casualty insurance industries }\end{array}$ & 349,377 \\
3 & $\begin{array}{l}\text { Firm-year observations with non-missing book value of assets greater than } \\
\text { or equal to \$1 million dollars }\end{array}$ & 141,121 \\
4 & $\begin{array}{l}\text { Firm-year observations after deleting observations with missing values for } \\
\text { sales, total assets, or net income before extraordinary items }\end{array}$ & 136,095 \\
& $\begin{array}{l}\text { Firm-year observations after eliminating observations with an absolute } \\
\text { value of external financing, external equity financing, or external debt } \\
\text { financing greater than 1 }\end{array}$ & 133,242 \\
& $\begin{array}{l}\text { Firm-year observations after eliminating observations with an absolute } \\
\text { value of total accruals or current accruals greater than 1 }\end{array}$ & 131,778 \\
\hline
\end{tabular}


Table 2: Variable Measurement

Variable

\section{Measurement (\#Compustat item numbers)}

\section{Panel A: Accruals and other variables}

Total accruals (TACC)

Current accruals (CACC)

Net debt financing $(\Delta \mathrm{Debt})$

Net equity financing ( $\Delta$ Equity)

Net external financing $(\triangle \mathrm{XFIN})$

Change in cash balance ( $\triangle \mathrm{CASH})$

Net income (INCOME)

Change in net operating assets (DNOA)

Change in net current operating assets (DCO)

Change in net non-current operating assets (DNCO)
Total accruals / average total assets (\#6). Total accruals, defined as income before extraordinary items (\#123) minus cash from operations (CFO, data 308$)$ divided by average total assets.

Current accruals / average total assets. Current accruals, defined as the increase in account receivables (\#302) plus the increase in inventory (\#303) minus the increase in account payable (\#304) minus the increase in tax payable (\#305) minus the net change in other current assets (\#307). That is, CACC $=-(\# 302+\# 303+\# 304$ $+\# 305+\# 307)$ / average total assets.

The cash proceeds from the issuance of long-term debt (\#111) less cash payments for long-term debt reduction (\#114) less the net changes in current debt (\#301) divided by average total assets.

The proceeds from the sale of common and preferred stock (\#108) less cash payments for the purchase of common and preferred stock (\#115) less cash payments for dividends (\#127) divided by average total assets.

The sum of net debt financing and net equity financing.

The change in the balance of cash and short-term investment (\#274) divided by average total assets.

Income before extraordinary items (\#123) divided by average total assets.

The change in net operating assets (NOA) divided by average total assets. Net operating asset $(\mathrm{NOA})=$ noncash assets $(\# 6-\# 1)$ minus noncash liabilities (\#181 - \#9 - \#34).

The change in net current operating assets divided by average total assets. Net current operating assets $=$ current operating assets $(\mathrm{COA})$ - current operating liabilities $(\mathrm{COL})$, where $\mathrm{COA}=$ current assets (\#4) - cash and shot term investment $(\# 1)$. COL = current liabilities (\#5) - debt in current liabilities (\#34).

The change in net non-current operating assets divided by average total assets. Net non-current operating assets = non-current operating assets (NCOA) - non-current operating liabilities $(\mathrm{NCOL})$, where NCOA $=$ total assets $(\# 6)$ - current assets (\#4) - 
investments and advances (\#32). NCOL $=$ total liabilities $(\# 181)-$ current liabilities (\#5) - long-term debt (\#9).

$\mathrm{PART}_{\triangle \mathrm{XFIN}>\mathrm{Q} 3}$

The dummy variable taking value of 1 when the firm's $\triangle X F I N$ is higher than the $75^{\text {th }}$ percentile of the distribution in the corresponding year, and zero otherwise.

$\mathrm{PART}_{\triangle \mathrm{XFIN}<\mathrm{Q} 1}$ The dummy variable taking value of 1 when the firm's $\triangle \mathrm{XFIN}$ is lower than the $25^{\text {th }}$ percentile of the distribution in the corresponding year, and zero otherwise

\section{Panel B: Determinants of fundamental accruals variability}

\begin{tabular}{|c|c|}
\hline UEXAC_MJT & $\begin{array}{l}\text { Unexpected accruals from the modified Jones model for total } \\
\text { accruals (TACC). }\end{array}$ \\
\hline UEXAC_MJT_ROA & $\begin{array}{l}\text { Unexpected accruals from the modified Jones model with ROA as } \\
\text { an additional regressor for total accruals (TACC). }\end{array}$ \\
\hline UEXAC_PMJT & $\begin{array}{l}\text { Performance-matched unexpected accruals based on the modified } \\
\text { Jones model for total accruals (TACC), as in Kothari et al. (2005). }\end{array}$ \\
\hline UEXAC_MJC & $\begin{array}{l}\text { Unexpected accruals from the modified Jones model for current } \\
\text { accruals (CACC). }\end{array}$ \\
\hline UEXAC_MJC_ROA & $\begin{array}{l}\text { Unexpected accruals from the modified Jones model with ROA as } \\
\text { an additional regressor for current accruals (CACC). }\end{array}$ \\
\hline UEXAC_PMJC & $\begin{array}{l}\text { Performance-matched unexpected accruals based on the modified } \\
\text { Jones model for current accruals (CACC), as in Kothari et al. } \\
(2005) \text {. }\end{array}$ \\
\hline UEXAC_DD & Unexpected accruals from the Dechow-Dichev model. \\
\hline UEXAC_DDM & $\begin{array}{l}\text { Unexpected accruals from the McNichols (2000)'s modification of } \\
\text { the Dechow-Dichev model. }\end{array}$ \\
\hline
\end{tabular}




\section{Table 3: Summary Statistics}

This Table presents the summary statistics of accruals measures, external financing variables and other variables. The measurement of all variables can be found in Table 2. All variables are deflated by average total assets and reported in percentage. The number of observations is 131,778.

\begin{tabular}{|c|c|c|c|c|c|}
\hline Variables & MEAN & STD & Lower Quartile & MEDIAN & Upper Quartile \\
\hline \multicolumn{6}{|c|}{ Panel A: Accruals, external financing and decomposition } \\
\hline TACC & -6.61 & 11.95 & -10.79 & -5.28 & -0.80 \\
\hline CACC & 1.38 & 8.73 & -2.35 & 0.88 & 5.06 \\
\hline$\triangle \mathrm{XFIN}$ & 4.34 & 16.55 & -4.03 & 0.00 & 7.02 \\
\hline$\triangle \mathrm{DEBT}$ & 1.37 & 10.30 & -2.58 & 0.00 & 3.75 \\
\hline$\triangle E Q U I T Y$ & 2.97 & 12.63 & -1.54 & 0.00 & 0.85 \\
\hline$\triangle \mathrm{CASH}$ & 0.69 & 10.22 & -1.99 & 0.07 & 2.87 \\
\hline $\mathrm{NI}$ & -2.52 & 18.62 & -4.88 & 2.81 & 7.07 \\
\hline DNOA & 4.89 & 20.05 & -4.18 & 3.22 & 13.14 \\
\hline DCO & 0.87 & 9.16 & -2.83 & 0.56 & 4.67 \\
\hline $\mathrm{DNCO}$ & 4.02 & 15.30 & -2.40 & 1.58 & 7.97 \\
\hline
\end{tabular}

Panel B: Unexpected accruals without control for $\triangle \mathrm{XFIN}$

\begin{tabular}{lccccc}
\hline UEXAC_MJT & 0.00 & 10.52 & -3.74 & 0.80 & 5.15 \\
UEXAC_MJT_ROA & 0.00 & 8.76 & -3.91 & 0.22 & 4.22 \\
UEXAC_PMJT & -0.02 & 12.85 & -6.29 & 0.00 & 6.29 \\
UEXAC_MJC & 0.00 & 7.87 & -3.52 & -0.09 & 3.50 \\
UEXAC_MJC_ROA & 0.00 & 7.44 & -3.49 & -0.21 & 3.34 \\
UEXAC_PMJC & 0.00 & 10.72 & -5.39 & 0.00 & 5.43 \\
UEXAC_DD & 0.00 & 6.93 & -2.94 & -0.05 & 3.02 \\
UEXAC_DDM & 0.00 & 6.05 & -2.55 & 0.06 & 2.74 \\
\hline
\end{tabular}

Panel C: Unexpected accruals matched on $\triangle \mathrm{XFIN}$

\begin{tabular}{lccccc}
\hline UEXAC_MJT & -0.02 & 14.33 & -6.66 & 0.00 & 6.63 \\
UEXAC_MJT_ROA & -0.03 & 11.54 & -5.84 & 0.00 & 5.77 \\
UEXAC_MJC & -0.01 & 10.62 & -5.28 & 0.00 & 5.28 \\
UEXAC_MJC_ROA & -0.01 & 9.88 & -5.00 & 0.00 & 4.99 \\
UEXAC_DD & -0.05 & 9.51 & -4.52 & -0.01 & 4.45 \\
UEXAC_DDM & -0.05 & 8.40 & -4.07 & 0.00 & 4.00 \\
\hline
\end{tabular}

Panel D: Unexpected accruals with $\triangle \mathrm{XFIN}$ as an additional regressor

\begin{tabular}{lccccc}
\hline UEXAC_MJT & 0.00 & 10.04 & -3.57 & 0.76 & 4.92 \\
UEXAC_MJT_ROA & 0.00 & 8.00 & -3.63 & 0.27 & 3.99 \\
UEXAC_PMJT & -0.07 & 12.19 & -6.03 & 0.00 & 5.92 \\
UEXAC_MJC & 0.00 & 7.41 & -3.27 & 0.01 & 3.38 \\
UEXAC_MJC_ROA & 0.00 & 6.84 & -3.21 & -0.06 & 3.17 \\
UEXAC_PMJC & 0.00 & 10.03 & -5.05 & 0.00 & 5.11 \\
UEXAC_DD & 0.00 & 6.61 & -2.79 & 0.01 & 2.89 \\
UEXAC_DDM & 0.00 & 5.80 & -2.44 & 0.06 & 2.61 \\
\hline
\end{tabular}

TACC is total accruals, defined as income before extraordinary items (\#123) minus cash from operations (CFO, data 308). CACC is current accruals, defined as the increase in account receivables (\#302) plus the increase in inventory (\#303) minus the increase in account payable (\#304) minus the increase in tax payable (\#305) minus the net change in other current assets (\#307). $\triangle \mathrm{DEBT}$ is net debt financing measured as the cash proceeds from the issuance of long-term debt (\#111) less cash payments for long-term debt reduction (\#114) less the net changes in current debt (\#301). $\triangle E Q U I T Y$ is net equity 
financing measured as the proceeds from the sale of common and preferred stock (\#108) less cash payments for the purchase of common and preferred stock (\#115) less cash payments for dividends (\#127). $\triangle \mathrm{XFIN}$ is net external financing, defined as the sum of net debt financing and net equity financing. $\triangle \mathrm{CASH}$ is the change in the balance of cash and short-term investment (\#274). NI is income before extraordinary items (\#123). DNOA is the change in net operating assets (NOA), defined as noncash assets (\#6 - \#1) minus noncash liabilities (\#181 - \#9 - \#34). DCO is the change in net current operating assets, where net current operating assets are equal to current operating assets (COA) minus current operating liabilities (COL). COA $=$ current assets $(\# 4)-$ cash and shot term investment (\#1). $\mathrm{COL}=$ current liabilities (\#5) - debt in current liabilities (\#34). DNCO is the change in net non-current operating assets, where net non-current operating assets are defined as non-current operating assets (NCOA) minus non-current operating liabilities (NCOL). NCOA $=$ total assets (\#6) - current assets (\#4) - investments and advances (\#32). NCOL $=$ total liabilities (\#181) - current liabilities (\#5) - long-term debt (\#9). UEXAC_MJT is unexpected accruals from the modified Jones model for total accruals (TACC). UEXAC_MJT_ROA is unexpected accruals from the modified Jones model with ROA as an additional regressor for total accruals (TACC). UEXAC_PMJT is performance-matched unexpected accruals based on the modified Jones model for total accruals (TACC), as in Kothari et al. (2005). UEXAC_MJC is unexpected accruals from the modified Jones model for current accruals (CACC). UEXAC_MJC_ROA is unexpected accruals from the modified Jones model with ROA as an additional regressor for current accruals (CACC). UEXAC_PMJC is performance-matched unexpected accruals based on the modified Jones model for current accruals (CACC), as in Kothari et al. (2005). UEXAC_DD is unexpected accruals from the Dechow-Dichev model. UEXAC_DDM is unexpected accruals from McNichols (2000)'s modification of the Dechow-Dichev model. 


\section{Table 4: Correlation Matrix}

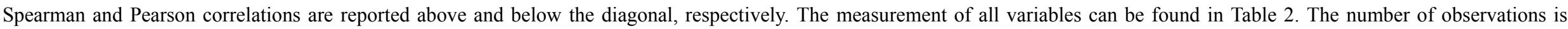
131,778 .

\begin{tabular}{|c|c|c|c|c|c|c|c|c|c|c|c|c|c|c|c|c|c|c|c|c|c|c|c|c|}
\hline & & & & & & & & & & & & MJT & & & & & MJT & & & & & MJT & & \\
\hline Variables & Tacc & Cacc & $\triangle \mathrm{XFIN}$ & $\Delta$ Debt & $\Delta$ Equity & $\Delta$ Cash & NI & DNOA & DCO & DNCO & MJT & ROA & PMJT & DD & DDM & MJT & ROA & PMJT & DD & DDM & MJT & ROA & DD & DDM \\
\hline TACC & - & 0.71 & 0.14 & 0.14 & -0.01 & -0.06 & 0.38 & 0.47 & 0.62 & 0.20 & 0.84 & 0.72 & 0.51 & 0.54 & 0.46 & 0.81 & 0.66 & 0.49 & 0.52 & 0.44 & 0.56 & 0.49 & 0.36 & 0.31 \\
\hline CACC & 0.69 & - & 0.22 & 0.16 & 0.09 & -0.09 & 0.25 & 0.52 & 0.76 & 0.17 & 0.64 & 0.60 & 0.41 & 0.78 & 0.68 & 0.62 & 0.54 & 0.39 & 0.74 & 0.65 & 0.42 & 0.39 & 0.51 & 0.46 \\
\hline$\triangle \mathrm{XFIN}$ & 0.06 & 0.17 & - & 0.66 & 0.53 & 0.10 & -0.19 & 0.43 & 0.23 & 0.35 & 0.13 & 0.25 & 0.16 & 0.15 & 0.10 & 0.07 & 0.06 & 0.12 & 0.05 & 0.04 & 0.00 & 0.00 & 0.00 & 0.00 \\
\hline$\triangle \mathrm{DEBT}$ & 0.08 & 0.13 & 0.55 & - & -0.05 & -0.03 & -0.04 & 0.36 & 0.18 & 0.31 & 0.13 & 0.20 & 0.12 & 0.08 & 0.05 & 0.10 & 0.08 & 0.10 & 0.04 & 0.04 & 0.03 & 0.03 & 0.00 & 0.01 \\
\hline$\triangle \mathrm{EQUITY}$ & 0.00 & 0.10 & 0.70 & -0.05 & - & 0.10 & -0.25 & 0.13 & 0.07 & 0.08 & 0.00 & 0.09 & 0.06 & 0.08 & 0.02 & -0.03 & 0.01 & 0.04 & 0.03 & 0.01 & -0.05 & -0.03 & 0.00 & -0.01 \\
\hline$\triangle \mathrm{CASH}$ & -0.01 & -0.06 & 0.20 & -0.01 & 0.25 & - & 0.18 & -0.08 & -0.10 & -0.02 & -0.09 & -0.17 & -0.11 & 0.00 & -0.03 & -0.10 & -0.25 & -0.13 & -0.04 & -0.04 & -0.07 & -0.15 & 0.00 & -0.02 \\
\hline NI & 0.51 & 0.24 & -0.24 & -0.06 & -0.22 & 0.17 & - & 0.33 & 0.25 & 0.27 & 0.28 & -0.05 & 0.00 & 0.35 & 0.26 & 0.28 & -0.06 & 0.01 & 0.34 & 0.26 & 0.23 & 0.02 & 0.27 & 0.19 \\
\hline DNOA & 0.44 & 0.46 & 0.41 & 0.36 & 0.19 & -0.03 & 0.28 & - & 0.58 & 0.77 & 0.41 & 0.35 & 0.23 & 0.44 & 0.31 & 0.38 & 0.23 & 0.21 & 0.39 & 0.29 & 0.26 & 0.18 & 0.27 & 0.20 \\
\hline DCO & 0.59 & 0.75 & 0.18 & 0.15 & 0.10 & -0.07 & 0.25 & 0.53 & - & 0.15 & 0.54 & 0.48 & 0.33 & 0.60 & 0.48 & 0.52 & 0.42 & 0.32 & 0.56 & 0.46 & 0.34 & 0.30 & 0.39 & 0.32 \\
\hline DNCO & 0.18 & 0.12 & 0.37 & 0.33 & 0.16 & 0.00 & 0.18 & 0.80 & 0.12 & - & 0.15 & 0.11 & 0.06 & 0.17 & 0.06 & 0.13 & 0.01 & 0.04 & 0.13 & 0.06 & 0.09 & 0.02 & 0.09 & 0.03 \\
\hline \multicolumn{25}{|c|}{ Without control for XFIN } \\
\hline $\begin{array}{l}\text { UEXAC_MJT } \\
\text { UEXAC MJT }\end{array}$ & 0.91 & 0.63 & 0.06 & 0.07 & 0.00 & -0.04 & 0.43 & 0.39 & 0.53 & 0.15 & - & 0.83 & 0.60 & 0.51 & 0.53 & 0.96 & 0.76 & 0.59 & 0.50 & 0.50 & 0.65 & 0.57 & 0.34 & 0.35 \\
\hline ROA & 0.78 & 0.63 & 0.21 & 0.16 & 0.11 & -0.14 & 0.05 & 0.35 & 0.51 & 0.13 & 0.85 & - & 0.63 & 0.40 & 0.40 & 0.81 & 0.92 & 0.61 & 0.39 & 0.38 & 0.55 & 0.64 & 0.25 & 0.26 \\
\hline UEXAC_PMJT & 0.55 & 0.43 & 0.14 & 0.10 & 0.08 & -0.09 & 0.02 & 0.23 & 0.34 & 0.07 & 0.63 & 0.67 & - & 0.27 & 0.30 & 0.58 & 0.57 & 0.88 & 0.27 & 0.29 & 0.42 & 0.42 & 0.17 & 0.21 \\
\hline UEXAC_DD & 0.57 & 0.83 & 0.11 & 0.06 & 0.09 & 0.04 & 0.36 & 0.40 & 0.63 & 0.13 & 0.54 & 0.45 & 0.29 & - & 0.85 & 0.50 & 0.35 & 0.27 & 0.95 & 0.81 & 0.33 & 0.26 & 0.65 & 0.56 \\
\hline UEXAC_DDM & 0.49 & 0.74 & 0.05 & 0.02 & 0.02 & 0.00 & 0.31 & 0.27 & 0.51 & 0.03 & 0.54 & 0.43 & 0.30 & 0.89 & - & 0.52 & 0.35 & 0.29 & 0.82 & 0.96 & 0.35 & 0.27 & 0.57 & 0.67 \\
\hline \multicolumn{25}{|c|}{ Control for XFIN: Regressed on XFIN } \\
\hline $\begin{array}{l}\text { UEXAC_MJT } \\
\text { UEXAC_MJT }\end{array}$ & 0.89 & 0.61 & 0.00 & 0.05 & -0.03 & -0.06 & 0.45 & 0.38 & 0.52 & 0.14 & 0.98 & 0.84 & 0.61 & 0.53 & 0.54 & - & 0.79 & 0.60 & 0.51 & 0.51 & 0.66 & 0.57 & 0.34 & 0.36 \\
\hline _ROA ${ }^{-}$ & 0.72 & 0.57 & 0.00 & 0.04 & -0.02 & -0.25 & 0.04 & 0.24 & 0.44 & 0.03 & 0.79 & 0.94 & 0.62 & 0.40 & 0.38 & 0.81 & - & 0.60 & 0.39 & 0.35 & 0.53 & 0.65 & 0.25 & 0.24 \\
\hline UEXAC_PMJT & 0.53 & 0.41 & 0.12 & 0.08 & 0.07 & -0.12 & 0.03 & 0.21 & 0.33 & 0.05 & 0.61 & 0.66 & 0.88 & 0.28 & 0.30 & 0.62 & 0.65 & - & 0.27 & 0.29 & 0.42 & 0.43 & 0.18 & 0.21 \\
\hline UEXAC_DD & 0.56 & 0.80 & 0.00 & 0.02 & 0.01 & -0.01 & 0.37 & 0.36 & 0.61 & 0.09 & 0.53 & 0.44 & 0.28 & 0.97 & 0.87 & 0.54 & 0.43 & 0.29 & - & 0.85 & 0.34 & 0.28 & 0.65 & 0.57 \\
\hline UEXAC_DDM & 0.48 & 0.72 & 0.00 & 0.01 & 0.00 & -0.01 & 0.31 & 0.26 & 0.50 & 0.02 & 0.53 & 0.42 & 0.30 & 0.86 & 0.97 & 0.53 & 0.39 & 0.30 & 0.89 & - & 0.34 & 0.27 & 0.56 & 0.65 \\
\hline \multicolumn{25}{|c|}{ Control for XFIN: Matched on XFIN } \\
\hline $\begin{array}{l}\text { UEXAC_MJT } \\
\text { UEXAC_MJT }\end{array}$ & 0.63 & 0.43 & 0.00 & 0.02 & -0.02 & -0.04 & 0.32 & 0.26 & 0.35 & 0.09 & 0.70 & 0.59 & 0.44 & 0.36 & 0.37 & 0.71 & 0.57 & 0.44 & 0.37 & 0.37 & - & 0.84 & 0.36 & 0.38 \\
\hline _ROA & 0.55 & 0.42 & 0.00 & 0.01 & -0.01 & -0.15 & 0.10 & 0.18 & 0.32 & 0.03 & 0.61 & 0.68 & 0.46 & 0.29 & 0.30 & 0.61 & 0.69 & 0.47 & 0.31 & 0.30 & 0.86 & - & 0.28 & 0.30 \\
\hline UEXAC_DD & 0.40 & 0.57 & 0.00 & -0.01 & 0.00 & 0.01 & 0.29 & 0.26 & 0.43 & 0.06 & 0.37 & 0.28 & 0.18 & 0.70 & 0.62 & 0.37 & 0.28 & 0.19 & 0.70 & 0.62 & 0.38 & 0.30 & - & 0.84 \\
\hline UEXAC_DDM & 0.34 & 0.51 & -0.01 & -0.01 & 0.00 & 0.00 & 0.23 & 0.18 & 0.35 & 0.01 & 0.37 & 0.29 & 0.21 & 0.62 & 0.71 & 0.38 & 0.27 & 0.21 & 0.63 & 0.70 & 0.39 & 0.31 & 0.87 & - \\
\hline
\end{tabular}




\section{Table 5: Sorting Analysis}

This Table reports the averages of unexpected accruals measures, external financing variables and other variables for the quartiles sorted on $\triangle \mathrm{XFIN}$ within each year, where quartile 1 (quartile 4) represents the lowest (highest) quartile. The measurement of all variables can be found in Table 2. All variables are deflated by average total assets and reported in percentage. The number of observations is 131,778.

\begin{tabular}{lcccc}
\hline Variables & $\begin{array}{r}\text { Quartile 1 } \\
\text { Panel A: Accruals, external financing and decomposition }\end{array}$ & $\begin{array}{c}\text { Quartile } 2 \\
\text { Quartile 3 }\end{array}$ & Quartile 4 \\
\hline TACC & -7.94 & -6.34 & -5.73 & -5.30 \\
CACC & 0.05 & 0.64 & 1.87 & 3.86 \\
$\Delta$ XFIN & -9.66 & -1.75 & 2.77 & 25.99 \\
$\Delta$ DEBT & -3.51 & -0.91 & 2.10 & 10.43 \\
$\Delta$ EQUITY & -1.45 & -0.74 & 0.86 & 13.46 \\
$\Delta$ CASH & 0.59 & -0.21 & -0.33 & 2.83 \\
NI & -1.31 & -0.12 & -2.10 & -7.50 \\
DNOA & 0.78 & 1.18 & 4.80 & 17.27 \\
DCO & -0.56 & 0.27 & 1.39 & 3.65 \\
DNCO & 1.51 & 1.04 & 3.31 & 12.31
\end{tabular}

Panel B: Unexpected accruals without control for $\triangle \mathrm{XFIN}$

\begin{tabular}{lllll}
\hline UEXAC_MJT & -1.08 & 0.17 & 0.62 & 1.21 \\
UEXAC_MJT_ROA & -1.40 & -0.48 & 0.46 & 2.69 \\
UEXAC_PMJT & -1.36 & -0.58 & 0.34 & 2.72 \\
UEXAC_MJC & -1.13 & -0.48 & 0.46 & 1.91 \\
UEXAC_MJC_ROA & -1.26 & -0.70 & 0.39 & 2.42 \\
UEXAC_PMJC & -1.30 & -0.60 & 0.47 & 2.34 \\
UEXAC_DD & -0.62 & -0.55 & 0.28 & 1.33 \\
UEXAC_DDM & -0.34 & -0.12 & 0.25 & 0.45
\end{tabular}

Panel C: Unexpected accruals matched on $\triangle \mathrm{XFIN}$

$\begin{array}{lcccc}\text { UEXAC_MJT } & -0.02 & -0.02 & 0.03 & -0.06 \\ \text { UEXAC_MJT_ROA } & -0.04 & -0.03 & -0.01 & -0.03 \\ \text { UEXAC_MJC } & -0.07 & -0.03 & 0.08 & -0.02 \\ \text { UEXAC_MJC_ROA } & -0.07 & 0.01 & 0.03 & -0.01 \\ \text { UEXAC_DD } & -0.05 & -0.07 & -0.05 & -0.02 \\ \text { UEXAC_DDM } & -0.06 & -0.06 & -0.03 & -0.05\end{array}$

Panel D: Unexpected accruals with $\triangle \mathrm{XFIN}$ as an additional regressor

\begin{tabular}{lllll}
\hline UEXAC_MJT & -0.86 & 0.19 & 0.41 & 0.26 \\
UEXAC_MJT_ROA & -0.98 & 0.17 & 0.64 & 0.18 \\
UEXAC_PMJT & -2.02 & -0.44 & 0.27 & 2.04 \\
UEXAC_MJC & -0.80 & -0.10 & 0.47 & 0.36 \\
UEXAC_MJC_ROA & -0.82 & -0.11 & 0.54 & 0.33 \\
UEXAC_PMJC & -1.32 & -0.27 & 0.51 & 0.99 \\
UEXAC_DD & -0.44 & -0.25 & 0.37 & 0.30 \\
UEXAC_DDM & -0.29 & -0.10 & 0.22 & 0.17 \\
\hline
\end{tabular}


Table 6: Bias in Testing Earnings Management in the Presence of External

\section{Financing}

This Table empirically estimates the bias in tests of earnings management (i.e., the bias in regression coefficients, $\left.\rho_{\mathrm{PART}, \eta} * \sigma_{\eta} / \sigma_{\mathrm{PART}}\right)$ in the presence of large external financing, by applying the framework as suggested by McNichols and Wilson (1988). The measurement of all variables can be found in Table 2. All variables are deflated by average total assets and reported in percentage. The number of observations is 131,778 . PART $\triangle \mathrm{XFIN}>\mathrm{Q} 3$ is an indicator variable equal to 1 if when the firm's $\triangle \mathrm{XFIN}$ is higher than the $75^{\text {th }}$ percentile of the distribution in the corresponding year, and zero otherwise. PART $_{\triangle \mathrm{XFIN}<Q 1}$ is an indicator variable equal to 1 if when the firm's $\triangle$ XFIN is lower than the $25^{\text {th }}$ percentile of the distribution in the corresponding year, and zero otherwise. $\eta$ is measured as the difference between unexpected accruals estimated from models without and with controlling for $\triangle \mathrm{XFIN}$.

\begin{tabular}{|c|c|c|}
\hline Unexpected accruals & $\operatorname{Bias}\left(\mathrm{PART}_{\triangle \mathrm{XFIN}>\mathrm{Q} 3}\right)$ & $\operatorname{Bias}\left(\mathrm{PART}_{\triangle \mathrm{XFIN}<\mathrm{Q} 1}\right)$ \\
\hline \multicolumn{3}{|c|}{ Panel A: Unexpected accruals matched on $\triangle \mathrm{XFIN}$ as the true model } \\
\hline UEXAC_MJT & 1.41 & -1.73 \\
\hline UEXAC_MJT_ROA & 3.53 & -3.14 \\
\hline UEXAC_MJC & 2.58 & -2.15 \\
\hline UEXAC_MJC_ROA & 3.30 & -2.60 \\
\hline UEXAC_DD & 1.74 & -1.23 \\
\hline UEXAC_DDM & 0.53 & -0.51 \\
\hline \multicolumn{3}{|c|}{ Panel B: Unexpected accruals with $\triangle \mathrm{XFIN}$ as an additional regressor as the true model } \\
\hline UEXAC_MJT & 1.03 & -0.73 \\
\hline UEXAC_MJT_ROA & 3.31 & -2.00 \\
\hline UEXAC_PMJT & 0.89 & -0.67 \\
\hline UEXAC_MJC & 2.07 & -1.32 \\
\hline UEXAC_MJC_ROA & 2.88 & -1.75 \\
\hline UEXAC_PMJC & 1.83 & -1.20 \\
\hline UEXAC_DD & 1.39 & -0.74 \\
\hline UEXAC_DDM & 0.32 & -0.20 \\
\hline
\end{tabular}




\section{Table 7: Regression of Unexpected Accruals on External Financing Indicators}

This Table reports results on regressing unexpected accruals on external financing indicators: UEXAC $=\alpha+\beta *$ PART $+\varepsilon$. The measurement of all variables can be found in Table 2. All variables are deflated by average total assets and reported in percentage. The number of observations is 131,778. $\mathrm{PART}_{\triangle \mathrm{XFIN}>\mathrm{Q} 3}$ is an indicator variable equal to 1 if when the firm's $\triangle \mathrm{XFIN}$ is higher than the $75^{\text {th }}$ percentile of the distribution in the corresponding year, and zero otherwise. $\mathrm{PART}_{\triangle \mathrm{XFIN}<\mathrm{Q} 1}$ is an indicator variable equal to 1 if when the firm's $\triangle$ XFIN is lower than the $25^{\text {th }}$ percentile of the distribution in the corresponding year, and zero otherwise. $* *(*)$ indicates significant at the $1 \%(5 \%)$ level for two tailed test.

\begin{tabular}{lcccc}
\hline Dependent variables & PART $_{\triangle \mathrm{XFIN}>\mathrm{Q} 3}$ & T-stat & PART $_{\triangle \mathrm{XFIN}<\mathrm{Q} 1}$ & T-stat \\
Panel A: Unexpected accruals & without control for $\Delta$ XFIN & & \\
\hline UEXAC_MJT & 1.68 & $4.8^{* *}$ & -2.17 & $-10.3^{* *}$ \\
UEXAC_MJT_ROA & 3.62 & $13.9^{* *}$ & -3.61 & $-21.8^{* *}$ \\
UEXAC_PMJT & 3.70 & $10.8^{* *}$ & -3.50 & $-15.6^{* *}$ \\
UEXAC_MJC & 2.66 & $11.1^{* *}$ & -2.56 & $-12.7^{* *}$ \\
UEXAC_MJC_ROA & 3.17 & $12.3^{* *}$ & -2.97 & $-14.6^{* *}$ \\
UEXAC_PMJC & 3.24 & $10.3^{* *}$ & -3.08 & $-13.9^{* *}$ \\
UEXAC_DD & 1.71 & $9.3^{* *}$ & -1.31 & $-9.4^{* *}$ \\
UEXAC_DDM & 0.63 & $4.7^{* *}$ & -0.62 & $-6.7^{* *}$
\end{tabular}

Panel B: Unexpected accruals matched on $\triangle \mathrm{XFIN}$

\begin{tabular}{lcccc}
\hline UEXAC_MJT & 0.08 & 0.3 & -0.21 & -1.6 \\
UEXAC_MJT_ROA & -0.04 & -0.2 & -0.05 & -0.3 \\
UEXAC_MJC & 0.27 & 1.5 & -0.12 & -1.1 \\
UEXAC_MJC_ROA & 0.06 & 0.5 & -0.02 & -0.1 \\
UEXAC_DD & -0.05 & -0.5 & 0.18 & 1.4 \\
UEXAC_DDM & 0.10 & 1.2 & 0.01 & 0.1
\end{tabular}

Panel C: Unexpected accruals with $\triangle \mathrm{XFIN}$ as an additional regressor

\begin{tabular}{lcccc}
\hline UEXAC_MJT & 0.66 & $3.0^{* *}$ & -1.35 & $-10.1^{* *}$ \\
UEXAC_MJT_ROA & 0.33 & $2.3^{*}$ & -1.39 & $-8.7^{* *}$ \\
UEXAC_PMJT & 2.95 & $12.1^{* *}$ & -2.75 & $-8.7^{* *}$ \\
UEXAC_MJC & 0.79 & $6.9^{* *}$ & -1.19 & $-11.6^{* *}$ \\
UEXAC_MJC_ROA & 0.51 & $5.6^{* *}$ & -1.10 & $-11.6^{* *}$ \\
UEXAC_PMJC & 1.78 & $6.0^{* *}$ & -1.82 & $-13.0^{* *}$ \\
UEXAC_DD & 0.53 & $5.9^{* *}$ & -0.55 & $-6.7^{* *}$ \\
UEXAC_DDM & 0.37 & $4.0^{* *}$ & -0.44 & $-7.8^{* *}$ \\
\hline
\end{tabular}




\section{Table 8: Bias in Testing Earnings Management as the percent of the sample}

\section{contaminated by external financing}

This Table empirically estimates the bias in tests of earnings management in the presence of large external financing, by applying the framework as suggested by McNichols and Wilson (1988). Panel A and $\mathrm{B}$ report the bias in regression coefficients (i.e. $\rho_{\mathrm{PART}, \eta} * \sigma_{\eta} / \sigma_{\mathrm{PART}}$ ). Panel $\mathrm{C}$ and $\mathrm{D}$ report the difference between unexpected accruals estimated from models with and without a control for $\triangle$ XFIN (i.e. $\eta$ ). The sample is contaminated at the $\mathrm{X} \%$ level by taking a random sample of $1,000 * \mathrm{X} \%$ without replacement from the subsample of firm-years with large external financing $\left(\mathrm{PART}_{\triangle \mathrm{XFIN}>\mathrm{Q} 3}=1\right.$ or $\left.\mathrm{PART}_{\triangle \mathrm{XFIN}<\mathrm{Q} 1}=1\right)$ and a random sample of $1,000 *(100 \%-\mathrm{X} \%)$ without replacement from the subsample of firm-years without large external financing $\left(\mathrm{PART}_{\triangle \mathrm{XFIN}>\mathrm{Q} 3}=0\right.$ and $\mathrm{PART}_{\triangle \mathrm{XFIN}<\mathrm{Q} 1}=0$ ). The measurement of all variables can be found in Table 2. All variables are deflated by average total assets and reported in percentage. The number of observations is 131,778. $\mathrm{PART}_{\triangle \mathrm{XFIN}>\mathrm{Q} 3}$ is an indicator variable equal to 1 if when the firm's $\triangle X F I N$ is higher than the $75^{\text {th }}$ percentile of the distribution in the corresponding year, and zero otherwise. $\mathrm{PART}_{\triangle \mathrm{XFIN}<\mathrm{Q} 1}$ is an indicator variable equal to 1 if when the firm's $\triangle$ XFIN is lower than the $25^{\text {th }}$ percentile of the distribution in the corresponding year, and zero otherwise.

\begin{tabular}{|c|c|c|c|c|c|c|c|c|c|c|}
\hline Contamination level (X) & $10 \%$ & $20 \%$ & $30 \%$ & $40 \%$ & $50 \%$ & $60 \%$ & $70 \%$ & $80 \%$ & $90 \%$ & Average \\
\hline \multicolumn{11}{|c|}{ Panel A1: Bias when unexpected accruals matched on $\triangle \mathrm{XFIN}$ is the true model $\left(\mathrm{PART}_{\triangle \mathrm{XFIN}>\mathrm{Q} 3}\right)$} \\
\hline UEXAC_MJT & 0.92 & 0.90 & 0.93 & 0.84 & 0.84 & 0.88 & 0.90 & 0.90 & 0.91 & 0.89 \\
\hline UEXAC_MJT_ROA & 2.74 & 2.72 & 2.73 & 2.71 & 2.73 & 2.69 & 2.69 & 2.68 & 2.70 & 2.71 \\
\hline UEXAC_MJC & 2.03 & 2.02 & 1.97 & 1.97 & 1.96 & 1.98 & 1.99 & 2.00 & 1.96 & 1.99 \\
\hline UEXAC_MJC_ROA & 2.58 & 2.58 & 2.60 & 2.60 & 2.59 & 2.59 & 2.58 & 2.56 & 2.53 & 2.58 \\
\hline UEXAC_DD & 1.39 & 1.42 & 1.42 & 1.40 & 1.39 & 1.38 & 1.39 & 1.41 & 1.34 & 1.39 \\
\hline UEXAC_DDM & 0.40 & 0.39 & 0.38 & 0.40 & 0.38 & 0.38 & 0.38 & 0.37 & 0.32 & 0.38 \\
\hline \multicolumn{11}{|c|}{ Panel A2: Bias when unexpected accruals matched on $\triangle \mathrm{XFIN}$ is the true model $\left(\mathrm{PART}_{\triangle \mathrm{XFIN}<\mathrm{Q} 1}\right)$} \\
\hline UEXAC_MJT & -1.67 & -1.66 & -1.66 & -1.66 & -1.69 & -1.63 & -1.62 & -1.64 & -1.62 & -1.65 \\
\hline UEXAC_MJT_ROA & -2.62 & -2.64 & -2.64 & -2.66 & -2.66 & -2.69 & -2.70 & -2.71 & -2.70 & -2.67 \\
\hline UEXAC_MJC & -1.88 & -1.84 & -1.86 & -1.84 & -1.85 & -1.85 & -1.84 & -1.81 & -1.87 & -1.85 \\
\hline UEXAC_MJC_ROA & -2.18 & -2.21 & -2.20 & -2.18 & -2.18 & -2.18 & -2.18 & -2.20 & -2.22 & -2.19 \\
\hline UEXAC_DD & -0.99 & -0.97 & -0.99 & -1.00 & -1.01 & -0.99 & -0.99 & -0.97 & -1.05 & -1.00 \\
\hline UEXAC_DDM & -0.47 & -0.44 & -0.45 & -0.46 & -0.47 & -0.47 & -0.49 & -0.50 & -0.55 & -0.48 \\
\hline
\end{tabular}

Panel B1: Bias when unexpected accruals with $\triangle \mathrm{XFIN}$ as an additional regressor is the true model $\left(\mathrm{PART}_{\triangle \mathrm{XFIN}>\mathrm{Q} 3}\right)$

$\begin{array}{lllllllllll}\text { UEXAC_MJT } & 0.85 & 0.86 & 0.87 & 0.87 & 0.87 & 0.86 & 0.87 & 0.87 & 0.87 & 0.86 \\ \text { UEXAC_MJT_ROA } & 2.90 & 2.90 & 2.89 & 2.89 & 2.90 & 2.88 & 2.89 & 2.89 & 2.90 & 2.89 \\ \text { UEXAC_PMJT } & 0.74 & 0.68 & 0.69 & 0.68 & 0.68 & 0.68 & 0.69 & 0.68 & 0.72 & 0.69 \\ \text { UEXAC_MJC } & 1.73 & 1.76 & 1.75 & 1.75 & 1.76 & 1.75 & 1.75 & 1.75 & 1.74 & 1.75 \\ \text { UEXAC_MJC_ROA } & 2.44 & 2.46 & 2.45 & 2.46 & 2.46 & 2.46 & 2.46 & 2.46 & 2.45 & 2.46 \\ \text { UEXAC_PMJC } & 1.52 & 1.54 & 1.51 & 1.53 & 1.56 & 1.56 & 1.56 & 1.56 & 1.54 & 1.54 \\ \text { UEXAC_DD } & 1.24 & 1.23 & 1.23 & 1.24 & 1.24 & 1.24 & 1.24 & 1.24 & 1.24 & 1.24 \\ \text { UEXAC_DDM } & 0.26 & 0.26 & 0.27 & 0.27 & 0.27 & 0.27 & 0.28 & 0.28 & 0.27 & 0.27\end{array}$

Panel B2: Bias when unexpected accruals with $\triangle \mathrm{XFIN}$ as an additional regressor is the true model $\left(\mathrm{PART}_{\triangle \mathrm{XFIN}<\mathrm{Q} 1}\right)$

$\begin{array}{lllllllllll}\text { UEXAC_MJT } & -0.57 & -0.56 & -0.56 & -0.56 & -0.56 & -0.56 & -0.55 & -0.55 & -0.56 & -0.56 \\ \text { UEXAC_MJT_ROA } & -1.36 & -1.36 & -1.37 & -1.37 & -1.36 & -1.37 & -1.37 & -1.37 & -1.35 & -1.36 \\ \text { UEXAC_PMJT } & -0.54 & -0.52 & -0.52 & -0.54 & -0.54 & -0.55 & -0.55 & -0.57 & -0.53 & -0.54 \\ \text { UEXAC_MJC } & -0.93 & -0.94 & -0.93 & -0.93 & -0.93 & -0.93 & -0.94 & -0.94 & -0.95 & -0.94 \\ \text { UEXAC_MJC_ROA } & -1.23 & -1.22 & -1.21 & -1.22 & -1.22 & -1.22 & -1.22 & -1.22 & -1.23 & -1.22 \\ \text { UEXAC_PMJC } & -0.91 & -0.89 & -0.89 & -0.90 & -0.89 & -0.87 & -0.88 & -0.88 & -0.89 & -0.89 \\ \text { UEXAC_DD } & -0.45 & -0.45 & -0.45 & -0.45 & -0.45 & -0.45 & -0.45 & -0.45 & -0.46 & -0.45 \\ \text { UEXAC_DDM } & -0.14 & -0.14 & -0.14 & -0.14 & -0.14 & -0.14 & -0.14 & -0.13 & -0.14 & -0.14\end{array}$


Panel C1: Difference between unexpected accruals without controlling for $\triangle \mathrm{XFIN}$ and matched on $\triangle \mathrm{XFIN}\left(\mathrm{PART}_{\triangle \mathrm{XFIN}>\mathrm{Q} 3}\right)$

$\begin{array}{lccccccccc}\text { UEXAC_MJT } & 0.47 & 0.57 & 0.65 & 0.73 & 0.82 & 0.89 & 0.97 & 1.07 & 1.16 \\ \text { UEXAC_MJT_ROA } & 0.27 & 0.54 & 0.81 & 1.08 & 1.35 & 1.62 & 1.90 & 2.17 & 2.43 \\ \text { UEXAC_MJC } & -0.03 & 0.17 & 0.37 & 0.56 & 0.75 & 0.96 & 1.16 & 1.36 & 1.55 \\ \text { UEXAC_MJC_ROA } & 0.06 & 0.32 & 0.59 & 0.86 & 1.12 & 1.38 & 1.64 & 1.91 & 2.16 \\ \text { UEXAC_DD } & 0.07 & 0.22 & 0.36 & 0.50 & 0.65 & 0.77 & 0.92 & 1.06 & 1.21 \\ \text { UEXAC_DDM } & 0.14 & 0.18 & 0.22 & 0.26 & 0.30 & 0.35 & 0.41 & 0.45 & 0.49\end{array}$

Panel C2: Difference between unexpected accruals without controlling for $\triangle \mathrm{XFIN}$ and matched on $\triangle \mathrm{XFIN}\left(\mathrm{PART}_{\triangle \mathrm{XFIN}<\mathrm{Q} 1}\right)$

$\begin{array}{lccccccccc}\text { UEXAC_MJT } & 0.21 & 0.05 & -0.12 & -0.27 & -0.44 & -0.62 & -0.80 & -0.96 & -1.12 \\ \text { UEXAC_MJT_ROA } & -0.26 & -0.53 & -0.80 & -1.07 & -1.35 & -1.61 & -1.87 & -2.14 & -2.42 \\ \text { UEXAC_MJC } & -0.22 & -0.40 & -0.59 & -0.77 & -0.95 & -1.14 & -1.32 & -1.50 & -1.68 \\ \text { UEXAC_MJC_ROA } & -0.42 & -0.63 & -0.84 & -1.05 & -1.27 & -1.48 & -1.69 & -1.90 & -2.11 \\ \text { UEXAC_DD } & -0.16 & -0.26 & -0.37 & -0.46 & -0.56 & -0.65 & -0.74 & -0.84 & -0.93 \\ \text { UEXAC_DDM } & 0.05 & 0.01 & -0.03 & -0.09 & -0.12 & -0.16 & -0.20 & -0.25 & -0.29\end{array}$

Panel D1: Difference between unexpected accruals without controlling for $\triangle \mathrm{XFIN}$ and with $\triangle \mathrm{XFIN}$ as an additional regressor $\left(\mathrm{PART}_{\triangle \mathrm{XFIN}>\mathrm{Q} 3}\right)$

$\begin{array}{lccccccccc}\text { UEXAC_MJT } & 0.18 & 0.26 & 0.35 & 0.44 & 0.52 & 0.61 & 0.70 & 0.78 & 0.87 \\ \text { UEXAC_MJT_ROA } & -0.12 & 0.17 & 0.46 & 0.75 & 1.04 & 1.32 & 1.61 & 1.90 & 2.19 \\ \text { UEXAC_PMJT } & 0.03 & 0.09 & 0.17 & 0.24 & 0.31 & 0.38 & 0.45 & 0.53 & 0.61 \\ \text { UEXAC_MJC } & -0.02 & 0.16 & 0.33 & 0.51 & 0.68 & 0.85 & 1.03 & 1.20 & 1.38 \\ \text { UEXAC_MJC_ROA } & -0.12 & 0.12 & 0.37 & 0.61 & 0.86 & 1.10 & 1.35 & 1.60 & 1.85 \\ \text { UEXAC_PMJC } & -0.04 & 0.11 & 0.26 & 0.42 & 0.57 & 0.73 & 0.88 & 1.04 & 1.19 \\ \text { UEXAC_DD } & -0.07 & 0.05 & 0.17 & 0.30 & 0.42 & 0.55 & 0.67 & 0.79 & 0.92 \\ \text { UEXAC_DDM } & 0.04 & 0.06 & 0.09 & 0.12 & 0.14 & 0.17 & 0.20 & 0.23 & 0.26\end{array}$

Panel D2: Difference between unexpected accruals without controlling for $\triangle \mathrm{XFIN}$ and with $\triangle \mathrm{XFIN}$ as an additional regressor $\left(\mathrm{PART}_{\triangle \mathrm{XFIN}<\mathrm{Q} 1}\right)$

\begin{tabular}{lccccccccc} 
UEXAC_MJT & 0.03 & -0.02 & -0.08 & -0.13 & -0.19 & -0.24 & -0.30 & -0.35 & -0.41 \\
UEXAC_MJT_ROA & -0.55 & -0.68 & -0.82 & -0.96 & -1.09 & -1.23 & -1.37 & -1.50 & -1.64 \\
UEXAC_PMJT & -0.10 & -0.15 & -0.20 & -0.24 & -0.30 & -0.36 & -0.41 & -0.47 & -0.52 \\
UEXAC_MJC & -0.29 & -0.38 & -0.48 & -0.57 & -0.66 & -0.75 & -0.85 & -0.94 & -1.04 \\
UEXAC_MJC_ROA & -0.49 & -0.61 & -0.73 & -0.86 & -0.98 & -1.10 & -1.22 & -1.35 & -1.47 \\
UEXAC_PMJC & -0.29 & -0.37 & -0.46 & -0.56 & -0.65 & -0.73 & -0.82 & -0.91 & -1.00 \\
UEXAC_DD & -0.24 & -0.29 & -0.33 & -0.38 & -0.42 & -0.47 & -0.51 & -0.56 & -0.61 \\
UEXAC_DDM & 0.00 & -0.02 & -0.03 & -0.05 & -0.06 & -0.08 & -0.09 & -0.10 & -0.12 \\
\hline
\end{tabular}




\section{Table 9: Rejection Frequencies as the percent of the sample contaminated by external financing (5\% significance level)}

This Table reports empirical rejection frequencies for samples contaminated by external financing. The sample is contaminated at the $\mathrm{X} \%$ level by taking a random sample of $1,000 * \mathrm{X} \%$ without replacement from the subsample of firm-years with large external financing $\left(\mathrm{PART}_{\triangle \mathrm{XFIN}>\mathrm{Q} 3}=1\right.$ or $\left.\mathrm{PART}_{\triangle \mathrm{XFIN}<\mathrm{Q} 1}=1\right)$ and a random sample of $1,000 *(100 \%-\mathrm{X} \%)$ without replacement from the subsample of firm-years without large external financing $\left(\mathrm{PART}_{\triangle \mathrm{XFIN}>\mathrm{Q} 3}=0\right.$ and $\left.\mathrm{PART}_{\triangle \mathrm{XFIN}<\mathrm{Q} 1}=0\right)$. $\mathrm{PART}_{\triangle \mathrm{XFIN}>\mathrm{Q} 3}$ is an indicator variable equal to 1 if when the firm's $\triangle \mathrm{XFIN}$ is higher than the $75^{\text {th }}$ percentile of the distribution in the corresponding year, and zero otherwise. $\mathrm{PART}_{\triangle \mathrm{XFIN}<\mathrm{Q} 1}$ is an indicator variable equal to 1 if when the firm's $\triangle X F I N$ is lower than the $25^{\text {th }}$ percentile of the distribution in the corresponding year, and zero otherwise. The rejection frequencies thus represent the percentage of 250 trials where tests of earnings management is significant at the $5 \%$ or $1 \%$ level and, hence, represents the probability of committing a type I error when some firms in the sample involve in large net external financing if no earnings management is present.

\begin{tabular}{|c|c|c|c|c|c|c|c|c|c|c|c|}
\hline $\begin{array}{l}\text { Contamination level } \\
\text { (X) }\end{array}$ & $0 \%$ & $10 \%$ & $20 \%$ & $30 \%$ & $40 \%$ & $50 \%$ & $60 \%$ & $70 \%$ & $80 \%$ & $90 \%$ & $100 \%$ \\
\hline
\end{tabular}

Panel A: Unexpected accruals without control for $\triangle \mathrm{XFIN}\left(\mathrm{PART}_{\triangle \mathrm{XFIN}>\mathrm{Q} 3}\right)$

\begin{tabular}{|c|c|c|c|c|c|c|c|c|c|c|c|}
\hline UEXAC MJT & $8.0 \%$ & $36.0 \%$ & $55.2 \%$ & $63.2 \%$ & $68.4 \%$ & $75.2 \%$ & $74.8 \%$ & $79.2 \%$ & $85.6 \%$ & $88.8 \%$ & $91.6 \%$ \\
\hline UEXAC_MJT_ROA & $3.6 \%$ & $26.4 \%$ & $66.4 \%$ & $89.6 \%$ & $99.2 \%$ & $100.0 \%$ & $100.0 \%$ & $100.0 \%$ & $100.0 \%$ & $100.0 \%$ & $100.0 \%$ \\
\hline UEXAC_PMJT & $2.0 \%$ & $11.2 \%$ & $32.4 \%$ & $59.6 \%$ & $77.6 \%$ & $92.0 \%$ & $97.2 \%$ & $100.0 \%$ & $100.0 \%$ & $100.0 \%$ & $100.0 \%$ \\
\hline UEXAC_MJC & $2.4 \%$ & $18.4 \%$ & $43.6 \%$ & $71.6 \%$ & $92.4 \%$ & $96.8 \%$ & $100.0 \%$ & $100.0 \%$ & $100.0 \%$ & $100.0 \%$ & $100.0 \%$ \\
\hline UEXAC_MJC_ROA & $2.0 \%$ & $10.4 \%$ & $48.4 \%$ & $84.0 \%$ & $97.6 \%$ & $99.6 \%$ & $100.0 \%$ & $100.0 \%$ & $100.0 \%$ & $100.0 \%$ & $100.0 \%$ \\
\hline UEXAC_PMJC & $3.6 \%$ & $11.6 \%$ & $33.6 \%$ & $64.4 \%$ & $86.0 \%$ & $96.0 \%$ & $98.8 \%$ & $100.0 \%$ & $100.0 \%$ & $100.0 \%$ & $100.0 \%$ \\
\hline UEXAC_DD & $2.0 \%$ & $10.8 \%$ & $25.6 \%$ & $40.4 \%$ & $60.8 \%$ & $82.4 \%$ & $95.6 \%$ & $99.2 \%$ & $99.6 \%$ & $100.0 \%$ & $100.0 \%$ \\
\hline UEXAC_DDM & $7.2 \%$ & $11.2 \%$ & $22.8 \%$ & $28.0 \%$ & $33.6 \%$ & $36.4 \%$ & $42.8 \%$ & $46.8 \%$ & $51.2 \%$ & $58.4 \%$ & $66.8 \%$ \\
\hline
\end{tabular}

Panel B: Unexpected accruals matched on $\triangle \mathrm{XFIN}\left(\mathrm{PART}_{\triangle \mathrm{XFIN}>\mathrm{Q} 3}\right)$

$\begin{array}{llllllllllll}\text { UEXAC_MJT } & 6.4 \% & 5.6 \% & 4.4 \% & 5.6 \% & 6.0 \% & 4.8 \% & 3.6 \% & 4.0 \% & 4.4 \% & 2.4 \% & 2.4 \% \\ \text { UEXAC_MJT_ROA } & 3.6 \% & 4.4 \% & 3.6 \% & 5.2 \% & 3.2 \% & 4.8 \% & 4.4 \% & 2.8 \% & 2.8 \% & 2.0 \% & 2.8 \% \\ \text { UEXAC_MJC } & 6.4 \% & 4.8 \% & 6.0 \% & 6.4 \% & 6.4 \% & 5.6 \% & 5.2 \% & 5.2 \% & 4.4 \% & 4.8 \% & 5.2 \% \\ \text { UEXAC_MJC_ROA } & 5.2 \% & 4.0 \% & 4.4 \% & 5.2 \% & 2.8 \% & 4.0 \% & 3.6 \% & 4.4 \% & 3.2 \% & 2.8 \% & 2.0 \% \\ \text { UEXAC_DD } & 2.8 \% & 3.2 \% & 3.2 \% & 4.8 \% & 3.6 \% & 2.0 \% & 2.0 \% & 2.0 \% & 2.0 \% & 2.0 \% & 2.0 \% \\ \text { UEXAC_DDM } & 2.0 \% & 3.6 \% & 4.0 \% & 2.0 \% & 2.0 \% & 2.0 \% & 2.8 \% & 4.0 \% & 2.4 \% & 2.0 \% & 3.6 \%\end{array}$

Panel C: Unexpected accruals with $\triangle \mathrm{XFIN}$ as an additional regressor $\left(\mathrm{PART}_{\triangle \mathrm{XFIN}>\mathrm{Q} 3}\right)$

\begin{tabular}{|c|c|c|c|c|c|c|c|c|c|c|c|}
\hline UEXAC_MJT & $28.4 \%$ & $25.6 \%$ & $25.2 \%$ & $26.0 \%$ & $26.8 \%$ & $24.0 \%$ & $20.8 \%$ & $17.2 \%$ & $16.8 \%$ & $16.8 \%$ & $13.2 \%$ \\
\hline UEXAC_MJT_ROA & $44.8 \%$ & $38.8 \%$ & $32.0 \%$ & $26.4 \%$ & $22.0 \%$ & $23.2 \%$ & $20.0 \%$ & $18.0 \%$ & $19.6 \%$ & $17.6 \%$ & $14.8 \%$ \\
\hline UEXAC_PMJT & $4.0 \%$ & $10.4 \%$ & $26.4 \%$ & $43.2 \%$ & $61.6 \%$ & $79.6 \%$ & $88.4 \%$ & $93.2 \%$ & $96.0 \%$ & $99.2 \%$ & $99.2 \%$ \\
\hline UEXAC_MJC & $21.2 \%$ & $23.6 \%$ & $24.0 \%$ & $26.0 \%$ & $30.0 \%$ & $29.6 \%$ & $31.6 \%$ & $33.2 \%$ & $29.6 \%$ & $30.8 \%$ & $30.4 \%$ \\
\hline UEXAC_MJC_ROA & $26.4 \%$ & $28.8 \%$ & $29.2 \%$ & $26.0 \%$ & $25.6 \%$ & $30.0 \%$ & $31.6 \%$ & $31.2 \%$ & $32.8 \%$ & $30.8 \%$ & $33.6 \%$ \\
\hline UEXAC_PMJC & $16.0 \%$ & $22.0 \%$ & $30.8 \%$ & $38.4 \%$ & $46.4 \%$ & $53.2 \%$ & $59.2 \%$ & $66.0 \%$ & $71.2 \%$ & $80.0 \%$ & $82.8 \%$ \\
\hline UEXAC_DD & $8.8 \%$ & $10.4 \%$ & $12.0 \%$ & $14.8 \%$ & $17.6 \%$ & $17.6 \%$ & $21.2 \%$ & $23.2 \%$ & $26.0 \%$ & $24.4 \%$ & $29.2 \%$ \\
\hline UEXAC_DDM & $8.8 \%$ & $8.4 \%$ & $10.4 \%$ & $9.6 \%$ & $11.6 \%$ & $12.4 \%$ & $13.2 \%$ & $17.6 \%$ & $19.2 \%$ & $18.4 \%$ & $20.8 \%$ \\
\hline \multicolumn{12}{|c|}{ Panel D: Unexpected accruals without control for $\triangle \mathrm{XFIN}\left(\mathrm{PART}_{\triangle \mathrm{XFIN}<\mathrm{Q} 1}\right)$} \\
\hline UEXAC_MJT & $2.0 \%$ & $2.8 \%$ & $4.0 \%$ & $10.0 \%$ & $19.6 \%$ & $32.4 \%$ & $49.6 \%$ & $67.6 \%$ & $82.0 \%$ & $92.8 \%$ & $96.0 \%$ \\
\hline UEXAC_MJT_ROA & $4.0 \%$ & $15.2 \%$ & $30.8 \%$ & $54.4 \%$ & $73.2 \%$ & $88.0 \%$ & $94.4 \%$ & $98.0 \%$ & $99.2 \%$ & $100.0 \%$ & $100.0 \%$ \\
\hline UEXAC_PMJT & $5.6 \%$ & $14.0 \%$ & $22.4 \%$ & $38.0 \%$ & $47.2 \%$ & $57.2 \%$ & $68.8 \%$ & $84.0 \%$ & $89.6 \%$ & $94.0 \%$ & $95.6 \%$ \\
\hline UEXAC_MJC & $4.8 \%$ & $13.2 \%$ & $27.6 \%$ & $48.8 \%$ & $65.6 \%$ & $77.6 \%$ & $89.2 \%$ & $96.4 \%$ & $97.6 \%$ & $98.4 \%$ & $99.2 \%$ \\
\hline UEXAC_MJC_ROA & $18.4 \%$ & $34.0 \%$ & $53.6 \%$ & $74.4 \%$ & $86.8 \%$ & $92.4 \%$ & $97.6 \%$ & $100.0 \%$ & $100.0 \%$ & $100.0 \%$ & $100.0 \%$ \\
\hline
\end{tabular}




$\begin{array}{lccccccccccc}\text { UEXAC_PMJC } & 7.2 \% & 14.4 \% & 21.6 \% & 38.0 \% & 52.4 \% & 68.8 \% & 82.4 \% & 90.8 \% & 93.2 \% & 96.8 \% & 99.2 \% \\ \text { UEXAC_DD } & 20.8 \% & 28.4 \% & 36.4 \% & 43.6 \% & 55.6 \% & 63.6 \% & 70.8 \% & 77.2 \% & 80.4 \% & 85.6 \% & 89.2 \% \\ \text { UEXAC_DDM } & 2.0 \% & 4.0 \% & 6.8 \% & 8.8 \% & 13.6 \% & 22.8 \% & 30.8 \% & 38.0 \% & 44.0 \% & 53.2 \% & 60.4 \%\end{array}$

Panel E: Unexpected accruals matched on $\triangle \mathrm{XFIN}\left(\mathrm{PART}_{\triangle \mathrm{XFIN}<\mathrm{Q} 1}\right)$

\begin{tabular}{|c|c|c|c|c|c|c|c|c|c|c|c|}
\hline UEXAC_MJT & $3.6 \%$ & $2.8 \%$ & $3.6 \%$ & $4.8 \%$ & $6.4 \%$ & $4.8 \%$ & $4.4 \%$ & $3.6 \%$ & $5.2 \%$ & $4.0 \%$ & $5.2 \%$ \\
\hline UEXAC_MJT_ROA & $4.4 \%$ & $5.2 \%$ & $6.4 \%$ & $6.8 \%$ & $7.2 \%$ & $6.0 \%$ & $7.6 \%$ & $5.2 \%$ & $5.2 \%$ & $4.8 \%$ & $4.8 \%$ \\
\hline UEXAC_MJC & $4.4 \%$ & $5.2 \%$ & $3.6 \%$ & $5.6 \%$ & $8.0 \%$ & $7.6 \%$ & $6.4 \%$ & $7.6 \%$ & $7.6 \%$ & $8.0 \%$ & $7.6 \%$ \\
\hline UEXAC_MJC_ROA & $4.4 \%$ & $4.4 \%$ & $4.4 \%$ & $4.4 \%$ & $4.8 \%$ & $6.0 \%$ & $6.8 \%$ & $6.4 \%$ & $6.0 \%$ & $8.0 \%$ & $7.6 \%$ \\
\hline UEXAC_DD & $7.6 \%$ & $6.0 \%$ & $7.6 \%$ & $8.0 \%$ & $7.6 \%$ & $7.2 \%$ & $8.0 \%$ & $6.8 \%$ & $8.0 \%$ & $7.2 \%$ & $6.8 \%$ \\
\hline JEXAC DDM & $7.2 \%$ & $7.2 \%$ & $8.0 \%$ & $7.2 \%$ & $8.0 \%$ & $7.6 \%$ & $7.6 \%$ & $7.6 \%$ & $7.2 \%$ & $8.0 \%$ & $6.8 \%$ \\
\hline
\end{tabular}

Panel F: Unexpected accruals with $\triangle \mathrm{XFIN}$ as an additional regressor $\left(\mathrm{PART}_{\triangle \mathrm{XFIN}<\mathrm{Q} 1}\right)$

\begin{tabular}{lccccccccccc} 
UEXAC_MJT & $0.8 \%$ & $1.2 \%$ & $2.8 \%$ & $3.6 \%$ & $10.0 \%$ & $21.2 \%$ & $32.8 \%$ & $50.8 \%$ & $71.2 \%$ & $86.8 \%$ & $93.2 \%$ \\
UEXAC_MJT_ROA & $0.4 \%$ & $1.2 \%$ & $1.2 \%$ & $8.8 \%$ & $16.4 \%$ & $38.0 \%$ & $66.8 \%$ & $84.0 \%$ & $97.2 \%$ & $100.0 \%$ & $100.0 \%$ \\
UEXAC_PMJT & $4.8 \%$ & $16.0 \%$ & $32.8 \%$ & $56.4 \%$ & $75.2 \%$ & $89.6 \%$ & $96.8 \%$ & $99.6 \%$ & $99.6 \%$ & $100.0 \%$ & $100.0 \%$ \\
UEXAC_MJC & $0.4 \%$ & $0.4 \%$ & $3.6 \%$ & $12.4 \%$ & $27.2 \%$ & $43.6 \%$ & $64.0 \%$ & $80.4 \%$ & $88.8 \%$ & $97.2 \%$ & $99.2 \%$ \\
UEXAC_MJC_ROA & $0.4 \%$ & $0.4 \%$ & $3.2 \%$ & $13.6 \%$ & $22.8 \%$ & $43.6 \%$ & $64.8 \%$ & $81.6 \%$ & $91.6 \%$ & $98.8 \%$ & $100.0 \%$ \\
UEXAC_PMJC & $0.8 \%$ & $4.8 \%$ & $13.6 \%$ & $26.8 \%$ & $48.8 \%$ & $62.4 \%$ & $80.4 \%$ & $94.0 \%$ & $98.0 \%$ & $98.8 \%$ & $99.6 \%$ \\
UEXAC_DD & $3.2 \%$ & $4.0 \%$ & $8.4 \%$ & $11.6 \%$ & $18.8 \%$ & $26.0 \%$ & $39.2 \%$ & $48.0 \%$ & $58.8 \%$ & $70.4 \%$ & $77.6 \%$ \\
UEXAC_DDM & $2.4 \%$ & $4.4 \%$ & $4.8 \%$ & $8.4 \%$ & $12.8 \%$ & $16.0 \%$ & $20.8 \%$ & $27.6 \%$ & $36.4 \%$ & $49.2 \%$ & $57.6 \%$ \\
\hline
\end{tabular}




\section{Table 10: Rejection Frequencies as the percent of the sample contaminated by external financing (1\% significance level)}

This Table reports empirical rejection frequencies for samples contaminated by external financing. The sample is contaminated at the $\mathrm{X} \%$ level by taking a random sample of $1,000 * \mathrm{X} \%$ without replacement from the subsample of firm-years with large external financing $\left(\mathrm{PART}_{\triangle \mathrm{XFIN}>\mathrm{Q} 3}=1\right.$ or $\left.\mathrm{PART}_{\triangle \mathrm{XFIN}<\mathrm{Q} 1}=1\right)$ and a random sample of $1,000 *(100 \%-\mathrm{X} \%)$ without replacement from the subsample of firm-years without large external financing $\left(\mathrm{PART}_{\triangle \mathrm{XFIN}>\mathrm{Q} 3}=0\right.$ and $\mathrm{PART}_{\triangle \mathrm{XFIN}<\mathrm{Q} 1}=0$ ). $\mathrm{PART}_{\triangle \mathrm{XFIN}>\mathrm{Q} 3}$ is an indicator variable equal to 1 if when the firm's $\triangle \mathrm{XFIN}$ is higher than the $75^{\text {th }}$ percentile of the distribution in the corresponding year, and zero otherwise. $\mathrm{PART}_{\triangle \mathrm{XFIN}<\mathrm{Q} 1}$ is an indicator variable equal to 1 if when the firm's $\triangle X F I N$ is lower than the $25^{\text {th }}$ percentile of the distribution in the corresponding year, and zero otherwise. The rejection frequencies thus represent the percentage of 250 trials where tests of earnings management is significant at the $5 \%$ or $1 \%$ level and, hence, represents the probability of committing a type I error when some firms in the sample involve in large net external financing if no earnings management is present.

\begin{tabular}{|c|c|c|c|c|c|c|c|c|c|c|c|}
\hline $\begin{array}{l}\text { Contamination level } \\
\text { (X) }\end{array}$ & $0 \%$ & $10 \%$ & $20 \%$ & $30 \%$ & $40 \%$ & $50 \%$ & $60 \%$ & $70 \%$ & $80 \%$ & $90 \%$ & $100 \%$ \\
\hline
\end{tabular}

Panel A: Unexpected accruals without control for $\triangle \mathrm{XFIN}\left(\mathrm{PART}_{\triangle \mathrm{XFIN}>\mathrm{Q} 3}\right)$

\begin{tabular}{|c|c|c|c|c|c|c|c|c|c|c|c|}
\hline UEXAC_MJT & $4.0 \%$ & $21.2 \%$ & $35.2 \%$ & $40.2 \%$ & $46.4 \%$ & $50.4 \%$ & $57.2 \%$ & $64.0 \%$ & $66.4 \%$ & $72.0 \%$ & $75.6 \%$ \\
\hline UEXAC_MJT_ROA & $0.8 \%$ & $8.0 \%$ & $41.6 \%$ & $73.2 \%$ & $92.4 \%$ & $100.0 \%$ & $100.0 \%$ & $100.0 \%$ & $100.0 \%$ & $100.0 \%$ & $100.0 \%$ \\
\hline UEXAC_PMJT & $0.4 \%$ & $2.4 \%$ & $12.4 \%$ & $29.2 \%$ & $51.6 \%$ & $75.6 \%$ & $88.4 \%$ & $96.0 \%$ & $98.4 \%$ & $100.0 \%$ & $100.0 \%$ \\
\hline UEXAC_MJC & $0.8 \%$ & $5.2 \%$ & $20.4 \%$ & $46.8 \%$ & $69.6 \%$ & $88.4 \%$ & $97.6 \%$ & $100.0 \%$ & $100.0 \%$ & $100.0 \%$ & $100.0 \%$ \\
\hline UEXAC_MJC_ROA & $0.4 \%$ & $2.8 \%$ & $23.2 \%$ & $64.0 \%$ & $90.4 \%$ & $98.4 \%$ & $100.0 \%$ & $100.0 \%$ & $100.0 \%$ & $100.0 \%$ & $100.0 \%$ \\
\hline UEXAC_PMJC & $0.4 \%$ & $3.6 \%$ & $12.8 \%$ & $37.6 \%$ & $62.4 \%$ & $84.8 \%$ & $95.2 \%$ & $98.4 \%$ & $100.0 \%$ & $100.0 \%$ & $100.0 \%$ \\
\hline UEXAC_DD & $0.8 \%$ & $4.4 \%$ & $9.3 \%$ & $19.6 \%$ & $41.2 \%$ & $56.0 \%$ & $74.4 \%$ & $92.4 \%$ & $98.8 \%$ & $100.0 \%$ & $100.0 \%$ \\
\hline UEXAC_DDM & $2.8 \%$ & $4.4 \%$ & $8.4 \%$ & $12.0 \%$ & $18.8 \%$ & $22.4 \%$ & $24.4 \%$ & $26.4 \%$ & $28.8 \%$ & $30.0 \%$ & $32.4 \%$ \\
\hline
\end{tabular}

Panel B: Unexpected accruals matched on $\triangle \mathrm{XFIN}\left(\mathrm{PART}_{\triangle \mathrm{XFIN}>\mathrm{Q} 3}\right)$

$\begin{array}{llllllllllll}\text { UEXAC_MJT } & 2.8 \% & 2.4 \% & 1.6 \% & 2.4 \% & 0.8 \% & 0.8 \% & 0.8 \% & 1.2 \% & 0.8 \% & 0.8 \% & 0.4 \% \\ \text { UEXAC_MJT_ROA } & 1.2 \% & 1.2 \% & 0.8 \% & 0.8 \% & 0.4 \% & 0.8 \% & 0.8 \% & 0.8 \% & 0.8 \% & 0.8 \% & 0.4 \% \\ \text { UEXAC_MJC } & 0.4 \% & 0.8 \% & 0.4 \% & 0.4 \% & 0.8 \% & 0.8 \% & 0.4 \% & 0.4 \% & 1.2 \% & 0.4 \% & 0.8 \% \\ \text { UEXAC_MJC_ROA } & 0.8 \% & 1.2 \% & 1.2 \% & 0.4 \% & 0.8 \% & 0.4 \% & 0.8 \% & 1.2 \% & 0.8 \% & 0.4 \% & 0.4 \% \\ \text { UEXAC_DD } & 0.4 \% & 0.8 \% & 0.4 \% & 0.4 \% & 0.4 \% & 0.4 \% & 0.4 \% & 0.4 \% & 0.4 \% & 0.4 \% & 0.4 \% \\ \text { UEXAC_DDM } & 0.4 \% & 0.8 \% & 0.4 \% & 0.8 \% & 0.8 \% & 0.4 \% & 0.4 \% & 0.8 \% & 0.4 \% & 1.2 \% & 1.2 \%\end{array}$

Panel C: Unexpected accruals with $\triangle \mathrm{XFIN}$ as an additional regressor $\left(\mathrm{PART}_{\triangle \mathrm{XFIN}>\mathrm{Q} 3}\right)$

\begin{tabular}{|c|c|c|c|c|c|c|c|c|c|c|c|}
\hline UEXAC_MJT & $11.6 \%$ & $8.8 \%$ & $9.6 \%$ & $11.2 \%$ & $8.4 \%$ & $8.4 \%$ & $6.8 \%$ & $8.0 \%$ & $6.0 \%$ & $5.6 \%$ & $4.4 \%$ \\
\hline UEXAC_MJT_ROA & $23.6 \%$ & $20.4 \%$ & $15.2 \%$ & $11.6 \%$ & $6.4 \%$ & $4.8 \%$ & $5.2 \%$ & $5.6 \%$ & $4.4 \%$ & $3.6 \%$ & $3.6 \%$ \\
\hline UEXAC_PMJT & $0.8 \%$ & $1.6 \%$ & $9.6 \%$ & $22.4 \%$ & $33.2 \%$ & $54.4 \%$ & $70.0 \%$ & $82.4 \%$ & $90.8 \%$ & $93.6 \%$ & $98.0 \%$ \\
\hline UEXAC_MJC & $5.6 \%$ & $7.2 \%$ & $8.0 \%$ & $12.4 \%$ & $13.6 \%$ & $16.0 \%$ & $12.4 \%$ & $12.4 \%$ & $13.2 \%$ & $14.4 \%$ & $15.6 \%$ \\
\hline UEXAC_MJC_ROA & $8.8 \%$ & $8.0 \%$ & $6.8 \%$ & $8.0 \%$ & $6.0 \%$ & $10.8 \%$ & $9.6 \%$ & $13.6 \%$ & $12.0 \%$ & $11.2 \%$ & $11.6 \%$ \\
\hline UEXAC_PMJC & $4.0 \%$ & $8.4 \%$ & $10.4 \%$ & $16.4 \%$ & $23.6 \%$ & $32.0 \%$ & $36.8 \%$ & $38.8 \%$ & $45.6 \%$ & $55.6 \%$ & $64.4 \%$ \\
\hline UEXAC_DD & $1.2 \%$ & $2.8 \%$ & $2.8 \%$ & $4.0 \%$ & $5.2 \%$ & $4.8 \%$ & $8.0 \%$ & $9.2 \%$ & $8.8 \%$ & $8.8 \%$ & $9.2 \%$ \\
\hline UEXAC DDM & $1.6 \%$ & $2.4 \%$ & $3.6 \%$ & $3.6 \%$ & $4.4 \%$ & $4.8 \%$ & $4.0 \%$ & $4.0 \%$ & $6.8 \%$ & $4.4 \%$ & $6.4 \%$ \\
\hline
\end{tabular}

Panel D: Unexpected accruals without control for $\triangle \mathrm{XFIN}\left(\mathrm{PART}_{\triangle \mathrm{XFIN}<\mathrm{Q} 1}\right)$

\begin{tabular}{|c|c|c|c|c|c|c|c|c|c|c|c|}
\hline UEXAC_MJT & $0.8 \%$ & $0.8 \%$ & $0.8 \%$ & $2.4 \%$ & $4.0 \%$ & $13.2 \%$ & $24.0 \%$ & $38.0 \%$ & $59.2 \%$ & $74.4 \%$ & $86.8 \%$ \\
\hline UEXAC_MJT_ROA & $0.8 \%$ & $3.2 \%$ & $11.2 \%$ & $25.6 \%$ & $48.0 \%$ & $67.2 \%$ & $85.2 \%$ & $92.8 \%$ & $97.6 \%$ & $99.2 \%$ & $100.0 \%$ \\
\hline UEXAC_PMJT & $2.0 \%$ & $4.4 \%$ & $8.0 \%$ & $16.4 \%$ & $28.8 \%$ & $37.2 \%$ & $49.2 \%$ & $56.8 \%$ & $69.2 \%$ & $82.4 \%$ & $88.4 \%$ \\
\hline UEXAC_MJC & $0.8 \%$ & $2.8 \%$ & $9.2 \%$ & $20.8 \%$ & $36.4 \%$ & $52.0 \%$ & $70.8 \%$ & $85.2 \%$ & $94.4 \%$ & $95.6 \%$ & $97.2 \%$ \\
\hline UEXAC_MJC_ROA & $5.2 \%$ & $11.6 \%$ & $26.4 \%$ & $49.2 \%$ & $64.4 \%$ & $78.4 \%$ & $90.4 \%$ & $96.0 \%$ & $98.8 \%$ & $100.0 \%$ & $100.0 \%$ \\
\hline
\end{tabular}




\begin{tabular}{|c|c|c|c|c|c|c|c|c|c|c|c|}
\hline UEXAC_PMJC & $1.2 \%$ & $3.2 \%$ & $9.2 \%$ & $11.2 \%$ & $22.8 \%$ & $39.2 \%$ & $55.2 \%$ & $73.6 \%$ & $82.8 \%$ & $87.2 \%$ & $94.4 \%$ \\
\hline UEXAC_DD & $7.2 \%$ & $9.2 \%$ & $15.2 \%$ & $21.2 \%$ & $26.0 \%$ & $37.2 \%$ & $47.6 \%$ & $52.4 \%$ & $58.4 \%$ & $64.0 \%$ & $73.2 \%$ \\
\hline UEXAC DDM & $0.4 \%$ & $0.4 \%$ & $1.2 \%$ & $1.6 \%$ & $3.2 \%$ & $6.4 \%$ & $9.6 \%$ & $16.4 \%$ & $20.0 \%$ & $26.8 \%$ & $31.2 \%$ \\
\hline
\end{tabular}

Panel E: Unexpected accruals matched on $\triangle \mathrm{XFIN}\left(\mathrm{PART}_{\triangle \mathrm{XFIN}<\mathrm{Q} 1}\right)$

\begin{tabular}{|c|c|c|c|c|c|c|c|c|c|c|c|}
\hline UEXAC_MJT & $0.4 \%$ & $1.2 \%$ & $1.2 \%$ & $1.6 \%$ & $2.0 \%$ & $1.6 \%$ & $0.8 \%$ & $0.8 \%$ & $0.8 \%$ & $1.6 \%$ & $1.2 \%$ \\
\hline UEXAC_MJT_ROA & $0.8 \%$ & $1.6 \%$ & $0.8 \%$ & $2.4 \%$ & $1.2 \%$ & $1.6 \%$ & $1.6 \%$ & $1.6 \%$ & $1.6 \%$ & $1.6 \%$ & $0.8 \%$ \\
\hline UEXAC_MJC & $1.6 \%$ & $2.0 \%$ & $1.6 \%$ & $1.2 \%$ & $2.0 \%$ & $1.2 \%$ & $1.6 \%$ & $2.0 \%$ & $2.0 \%$ & $1.2 \%$ & $1.6 \%$ \\
\hline UEXAC_MJC_ROA & $0.4 \%$ & $0.8 \%$ & $0.8 \%$ & $1.2 \%$ & $1.2 \%$ & $1.6 \%$ & $1.2 \%$ & $1.6 \%$ & $2.0 \%$ & $0.4 \%$ & $2.4 \%$ \\
\hline UEXAC_DD & $2.8 \%$ & $2.0 \%$ & $1.6 \%$ & $2.8 \%$ & $1.6 \%$ & $1.6 \%$ & $2.0 \%$ & $0.8 \%$ & $1.6 \%$ & $1.6 \%$ & $1.6 \%$ \\
\hline UEXAC_DDM & $1.6 \%$ & $2.4 \%$ & $2.4 \%$ & $2.4 \%$ & $2.8 \%$ & $2.0 \%$ & $1.2 \%$ & $2.8 \%$ & $2.4 \%$ & $0.8 \%$ & $1.6 \%$ \\
\hline
\end{tabular}

Panel F: Unexpected accruals with $\triangle \mathrm{XFIN}$ as an additional regressor $\left(\mathrm{PART}_{\triangle \mathrm{XFIN}<\mathrm{Q} 1}\right)$

\begin{tabular}{|c|c|c|c|c|c|c|c|c|c|c|c|}
\hline UEXAC_MJT & $0.4 \%$ & $0.4 \%$ & $0.4 \%$ & $1.2 \%$ & $3.2 \%$ & $6.0 \%$ & $14.0 \%$ & $24.0 \%$ & $45.2 \%$ & $63.2 \%$ & $80.0 \%$ \\
\hline UEXAC_MJT_ROA & $0.4 \%$ & $0.4 \%$ & $0.4 \%$ & $0.4 \%$ & $5.6 \%$ & $14.8 \%$ & $34.4 \%$ & $62.0 \%$ & $83.2 \%$ & $96.0 \%$ & $99.6 \%$ \\
\hline UEXAC_PMJT & $1.2 \%$ & $4.8 \%$ & $12.0 \%$ & $33.6 \%$ & $56.4 \%$ & $75.2 \%$ & $90.0 \%$ & $96.4 \%$ & $98.8 \%$ & $99.6 \%$ & $100.0 \%$ \\
\hline UEXAC_MJC & $0.4 \%$ & $0.8 \%$ & $0.8 \%$ & $2.4 \%$ & $7.2 \%$ & $19.2 \%$ & $34.4 \%$ & $54.8 \%$ & $74.0 \%$ & $86.4 \%$ & $97.6 \%$ \\
\hline UEXAC_MJC_ROA & $0.4 \%$ & $0.4 \%$ & $0.4 \%$ & $3.2 \%$ & $9.2 \%$ & $16.8 \%$ & $36.4 \%$ & $58.8 \%$ & $76.8 \%$ & $93.2 \%$ & $98.0 \%$ \\
\hline UEXAC_PMJC & $0.8 \%$ & $0.8 \%$ & $3.6 \%$ & $10.4 \%$ & $24.0 \%$ & $40.8 \%$ & $58.4 \%$ & $77.2 \%$ & $91.2 \%$ & $96.8 \%$ & $98.8 \%$ \\
\hline UEXAC_DD & $0.4 \%$ & $1.2 \%$ & $1.6 \%$ & $4.0 \%$ & $6.4 \%$ & $8.8 \%$ & $12.4 \%$ & $22.0 \%$ & $32.4 \%$ & $47.2 \%$ & $56.0 \%$ \\
\hline UEXAC_DDM & $0.4 \%$ & $0.4 \%$ & $0.4 \%$ & $1.6 \%$ & $3.2 \%$ & $6.8 \%$ & $8.8 \%$ & $12.8 \%$ & $15.6 \%$ & $22.4 \%$ & $26.8 \%$ \\
\hline
\end{tabular}




\section{Table 11: Regression of Unexpected Accruals on External Debt and Equity}

\section{Financing Indicators}

This Table reports results on regressing unexpected accruals on external debt or equity financing indicators: UEXAC $=\alpha+\beta *$ PART $+\varepsilon$. The measurement of all variables can be found in Table 2 . All variables are deflated by average total assets and reported in percentage. The number of observations is 131,778 . $\mathrm{PART}_{\triangle \mathrm{DEBT}>\mathrm{Q} 3}$ is an indicator variable equal to 1 if when the firm's $\triangle \mathrm{DEBT}$ is higher than the $75^{\text {th }}$ percentile of the distribution in the corresponding year, and zero otherwise. $\mathrm{PART}_{\triangle \mathrm{DEBT}<\mathrm{Q} 1}$ is an indicator variable equal to 1 if when the firm's $\triangle \mathrm{DEBT}$ is lower than the $25^{\text {th }}$ percentile of the distribution in the corresponding year, and zero otherwise. $\mathrm{PART}_{\triangle \mathrm{EQUITY}>\mathrm{Q} 3}$ is an indicator variable equal to 1 if when the firm's $\triangle$ EQUITY is higher than the $75^{\text {th }}$ percentile of the distribution in the corresponding year, and zero otherwise. PART $\mathrm{PEQUITY}<\mathrm{Q} 1_{1}$ is an indicator variable equal to 1 if when the firm's $\triangle E Q U I T Y$ is lower than the $25^{\text {th }}$ percentile of the distribution in the corresponding year, and zero otherwise. ${ }^{* *}(*)$ indicates significant at the $1 \%(5 \%)$ level for two tailed test.

\begin{tabular}{|c|c|c|c|c|c|c|c|c|}
\hline \multirow{2}{*}{$\begin{array}{l}\text { External } \\
\text { indicators } \\
\text { Dependent } \\
\text { variables } \\
\end{array}$} & \multicolumn{4}{|c|}{ Debt Financing Indicator } & \multicolumn{4}{|c|}{ Equity Financing Indicator } \\
\hline & $\mathrm{PART}_{\triangle \mathrm{DEBT}>\mathrm{Q} 3}$ & T-stat & $\mathrm{PART}_{\triangle \mathrm{DEBT}<\mathrm{Q} 1}$ & T-stat & $\mathrm{PART}_{\triangle \mathrm{EQUITY}>\mathrm{Q} 3}$ & T-stat & $\mathrm{PART}_{\triangle \mathrm{EQUITY}<\mathrm{Q} 1}$ & T-stat \\
\hline \multicolumn{9}{|c|}{ Unexpected accruals without control for $\triangle$ XFIN } \\
\hline UEXAC_MJT & 1.91 & $7.00 * *$ & -2.44 & $-10.30 * *$ & 0.34 & 1.36 & 0.53 & $2.90 * *$ \\
\hline $\begin{array}{l}\text { UEXAC_MJT_R } \\
\text { OA }\end{array}$ & 3.25 & $13.29 * *$ & -2.82 & $-11.43^{* *}$ & 1.51 & $7.78^{* *}$ & -1.12 & $-7.75^{* *}$ \\
\hline UEXAC_PMJT & 2.81 & $7.83 * *$ & -2.54 & $-6.22 * *$ & 1.82 & $7.43 * *$ & -1.49 & $-7.01 * *$ \\
\hline UEXAC_MJC & 2.40 & $11.95 * *$ & -2.01 & $-9.62 * *$ & 1.53 & $5.71 * *$ & -0.44 & $-4.36^{* *}$ \\
\hline $\begin{array}{l}\text { UEXAC_MJC_R } \\
\text { OA }\end{array}$ & 2.78 & $13.61 * *$ & -2.10 & $-10.33 * *$ & 1.82 & $6.80 * *$ & -0.95 & $-7.87 * *$ \\
\hline UEXAC_PMJC & 2.61 & $10.70 * *$ & -1.89 & $-6.53 * *$ & 1.87 & $6.02 * *$ & -1.14 & $-6.67 * *$ \\
\hline UEXAC_DD & 1.20 & $8.13 * *$ & -0.81 & $-4.80 * *$ & 1.62 & $7.77 * *$ & -0.07 & -1.04 \\
\hline UEXAC_DDM & 0.56 & $4.45^{* *}$ & -0.36 & $-2.16^{*}$ & 0.63 & $4.87 * *$ & 0.11 & 1.37 \\
\hline
\end{tabular}


Table 12: Testing for Unexpected Accruals Concurrent with Share Repurchase

This Table reports estimated unexpected accruals across quartiles of net external debt financing $(\Delta$ Debt). The repurchase sample begins in 1988, the year in which the statement of cash flow data became available, and ends in 2002 consistent with Gong et al. (2008). UEXAC_AXFIN is unexpected accruals UEXAC_MJT by using the matching procedure based on industry and $\triangle$ XFIN. UEXAC_ $\triangle$ Debt is unexpected accruals UEXAC_MJT by using the matching procedure based on industry and $\Delta$ Debt. The measurement of other variables can be found in Table 2. All variables are deflated by average total assets and reported in percentage. Quartile $N$ for $\Delta$ Debt represents firms whose net external debt financing falls in the $\mathrm{N}^{\text {th }}$ quartile of the whole Compustat sample sorted on $\Delta$ Debt within each year, where quartile 1 (quartile 4) represents the lowest (highest) quartile. Robust $\mathrm{t}$-statistics (in parentheses) use a Huber-White correction for general heteroskedasticity in the standard errors. $* *(*)$ indicates significant at the $1 \%(5 \%)$ level for two tailed test.

\begin{tabular}{|c|c|c|c|c|c|}
\hline & UEXAC_MJT & UEXAC_PMJT & UEXAC_DDM & UEXAC_ $\triangle X F I N$ & $\begin{array}{l}\text { UEXAC_- } \\
\triangle \mathrm{Debt}\end{array}$ \\
\hline \multicolumn{6}{|c|}{ Panel A: Unexpected accruals for full sample of firms making share repurchase } \\
\hline Mean & -0.57 & -1.08 & 0.22 & 0.74 & 0.57 \\
\hline T-stat & $(-2.24)^{*}$ & $(-3.35)^{* *}$ & $(0.96)$ & $(1.85)$ & $(1.35)$ \\
\hline No. of Firms & 1050 & 1048 & 440 & 1005 & 1047 \\
\hline \multicolumn{6}{|c|}{$\begin{array}{l}\text { Panel B: Unexpected accruals for firms making share repurchase across quartiles of net external debt financing } \\
(\Delta \text { Debt })\end{array}$} \\
\hline \multicolumn{6}{|c|}{ Quartile 1 for $\Delta \mathrm{Debt}$} \\
\hline Mean & -1.85 & -1.56 & -0.02 & 0.45 & 1.11 \\
\hline T-stat & $(-3.01)^{* *}$ & $(-2.08)^{*}$ & $(-0.04)$ & $(0.51)$ & $(1.03)$ \\
\hline No. of Firms & 235 & 235 & 103 & 225 & 232 \\
\hline \multicolumn{6}{|c|}{ Quartile 2 for $\Delta \mathrm{Debt}$} \\
\hline Mean & -1.17 & -2.11 & -0.28 & 2.01 & 1.09 \\
\hline T-stat & $(-2.50)^{*}$ & $(-3.21)^{* *}$ & $(-0.74)$ & $(2.51)^{*}$ & $(1.38)$ \\
\hline No. of Firms & 269 & 268 & 122 & 252 & 269 \\
\hline \multicolumn{6}{|c|}{ Quartile 3 for $\Delta \mathrm{Debt}$} \\
\hline Mean & -0.88 & -1.07 & 0.13 & 0.06 & -0.28 \\
\hline T-stat & $(-1.89)$ & $(-2.18)^{*}$ & $(0.25)$ & $(0.09)$ & $(-0.37)$ \\
\hline No. of Firms & 281 & 281 & 101 & 270 & 281 \\
\hline \multicolumn{6}{|c|}{ Quartile 4 for $\Delta \mathrm{Debt}$} \\
\hline Mean & 1.47 & 0.66 & 1.04 & 0.45 & 0.47 \\
\hline T-stat & $(2.96)^{* *}$ & $(0.92)$ & $(2.87)^{* *}$ & $(0.53)$ & $(0.60)$ \\
\hline No. of Firms & 265 & 264 & 114 & 258 & 265 \\
\hline
\end{tabular}

